\title{
ARCHITECTURE OF HOT ZONES AND UTILIZATION OF SOLAR ENERGY (CASE STUDY IN ONE OF HADRAMOUT GOVERNORATE - AL -MUCALLA CITY)
}

\section{AL-Sagaf M.A}

Department of Architecture Environmental Planning, Faculty of engineering \& Petroleum Hadhramout University of science \& Technology

(Received August 27, 2008 Accepted August 2, 2009).

Yemen is one of countries that lie in the hot arid zone near the equator. In spite of the appropriateness of its traditional architecture to this type of climate, the new buildings suffer a lot of problems due to neglecting the climate issue. Large areas of glass have been adopted in many new building with no devices for avoiding high solar radiation. The present study is done of cases on exploring the concepts behind the traditional solutions. It presents examples of traditional architecture in Mukalla. It directs the attention of the important of adopting climatic design approach to avoid the harm effect of intense radiation, and at the same time make are of the abundance of solar radiation.

\section{عمارة المناطق الحارة ومدى الاستفادة والحماية من الطاقة الثمسية (دراسة حالة المناخ في مدينة المكلا إحدى مدن الساحل في محافظة حضرموت)

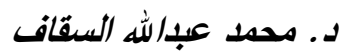$$
\text { قسم الهندسة المعدارية والتخطبط البييُي }
$$$$
\text { كلية العندسة والبترول - جامعة حضردوت للعلوم والثكنولوجيا }
$$

يتتاول البحث عمارة المناطق الحارة والتي تتنمي إليها الجمهورية اليمنية والتي تقع بالقرب من خط الاستواء. ونظرا لأهمية هذه الدراسـة في علاج مشاكل التتمية المعمارية والعمرانية التي تتتهجها الدولة في المدينة اليمنية وذلك نتيجة لظهور منشآت معماربة حديثة تفتقر الى اساليب الحماية من الطاقة الثمسية وأثعة الثمس حيث صممت مبانيها بفتحات ومسطحات زجاجية كبيرة لا تراعى فيها أسس تصميم المباني. لذلك فان الهدف من البحث هو إظهار وتوضيح اهمية علاج مشاكل الطاقة الثمسية وذلك بالتعرف على الاسـاليب التي انتهجها الأجداد في العمـارة الثراثيـة بالمدن ومدى تحقيـق الراحـة الحراريـة داخـل هذه المبـاني • وتتطرق الدراسـة الىى التعرف على العمـارة الثراثيـة باليمن والمكلا وحالة المنـاخ بها وطرق العـلاج التي ثم اتباعها في المناخ الحار ، كذك التعرف على تجارب البناء الحديث في بعض الدول العربية وطرق العلاج التي استخدمت في 
تصميم مبانيها. ويستعرض البحث طرق الحمايـة وأسس التصميم وكيفيـة الاستفاده من الطاقـة الثمسية. وينتهي البحث بعرض لأهم النتائج والتوصيات.

\section{المقدمة:}

تعتبر عمـارة المناطق الحارة ذات طابع مميز ، وقد تختلف من منطقة إلى أخرى في البلد الواحد ،

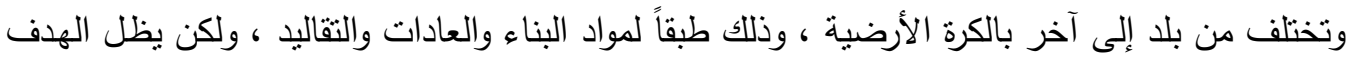

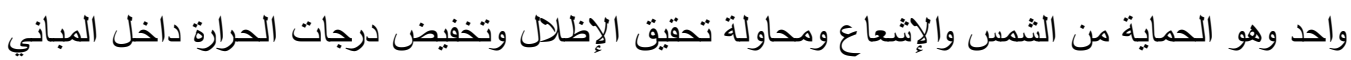
، الأمر الذي جعل دراسة هذه النواحي والتعرف عليها والاستفادة منها أمر في غاية الأهمية كذللك فإن إنان

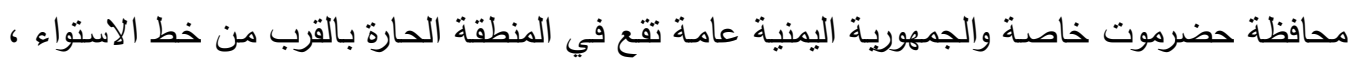
ودراسة عمارة مدينة الككلا عاصمة محافظة حضرموت هو نأكيد لأهمية هذه الدراسة.

\section{المشكلة:}

تتعرض المباني في مدينة المكلا منل مثيلاتها للبناء والتعمير والتوسع العمراني و إنثاء المباني السكنية

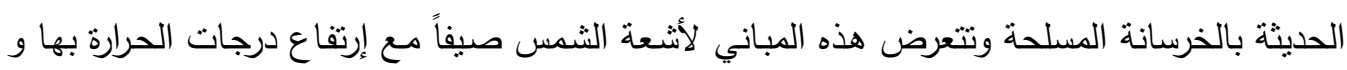
تتسبب في حدوث الإرهاق الحراري للسكان نتيجة لذلك.

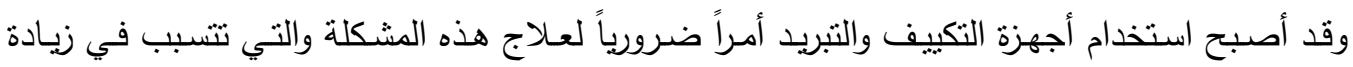
الإنفاق والذي يعد مشكلة حقيقية في هذا العصر وخصوصاً في عمارة الدناطق الحارة والبلاد النامية

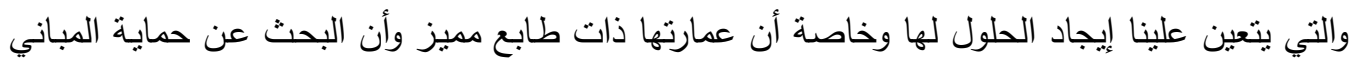

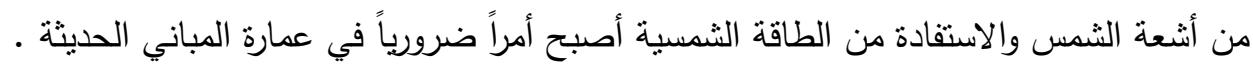

\section{الهدف:}

من أجل تحقيق علاج للمشكله البيئية لعمارة المناطق الحارة والتخفيف من حدة الحرارة الناتجة في فصل حلـ الصيف في مدينة المكلا عاصمة محافظة حضرموت والقريبة من خط الإستواء الجغرافي فإن دراسة لحنة

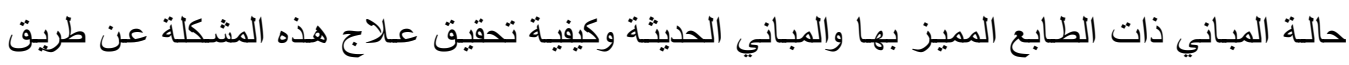

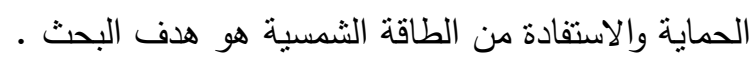
منهجية البحث: ونمانه لكي نتمكن من تحقيق الهدف البحثي يتعين علينا :

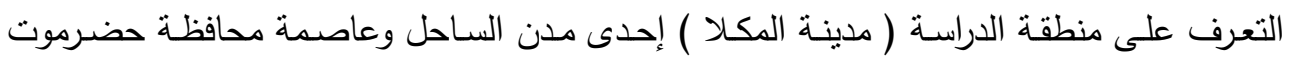

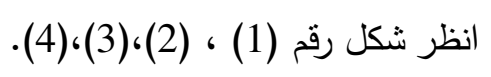

كذللك يتعين دراسة حالة المناخ ودرجات الحرارة والإشعاع الحراري صيفاً وأثره على البيئة السكنية . 
وتتنقل الدراسة إلى طبيعة البناء السكني بالمدينة (المكلا كمثال ) وهو البناء التقليدي ذو الطابع

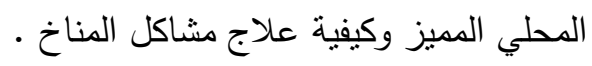
ثم نأتي إلى مشكلة البناء الحديث ومواد البناء وأثر الطاقة الثمسية والإثعاع الحراري عليها وطرق الحماية منه ثم الطابع المعماري الحديث للمباني ومشاكله . وأخيراً نتعرض الدراسة الى كيفية الاستفادة من الطاقة الثمسية لتحقيق الاهداف المرجوة .

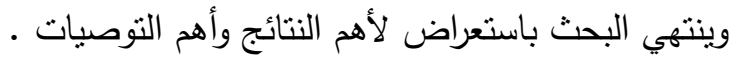

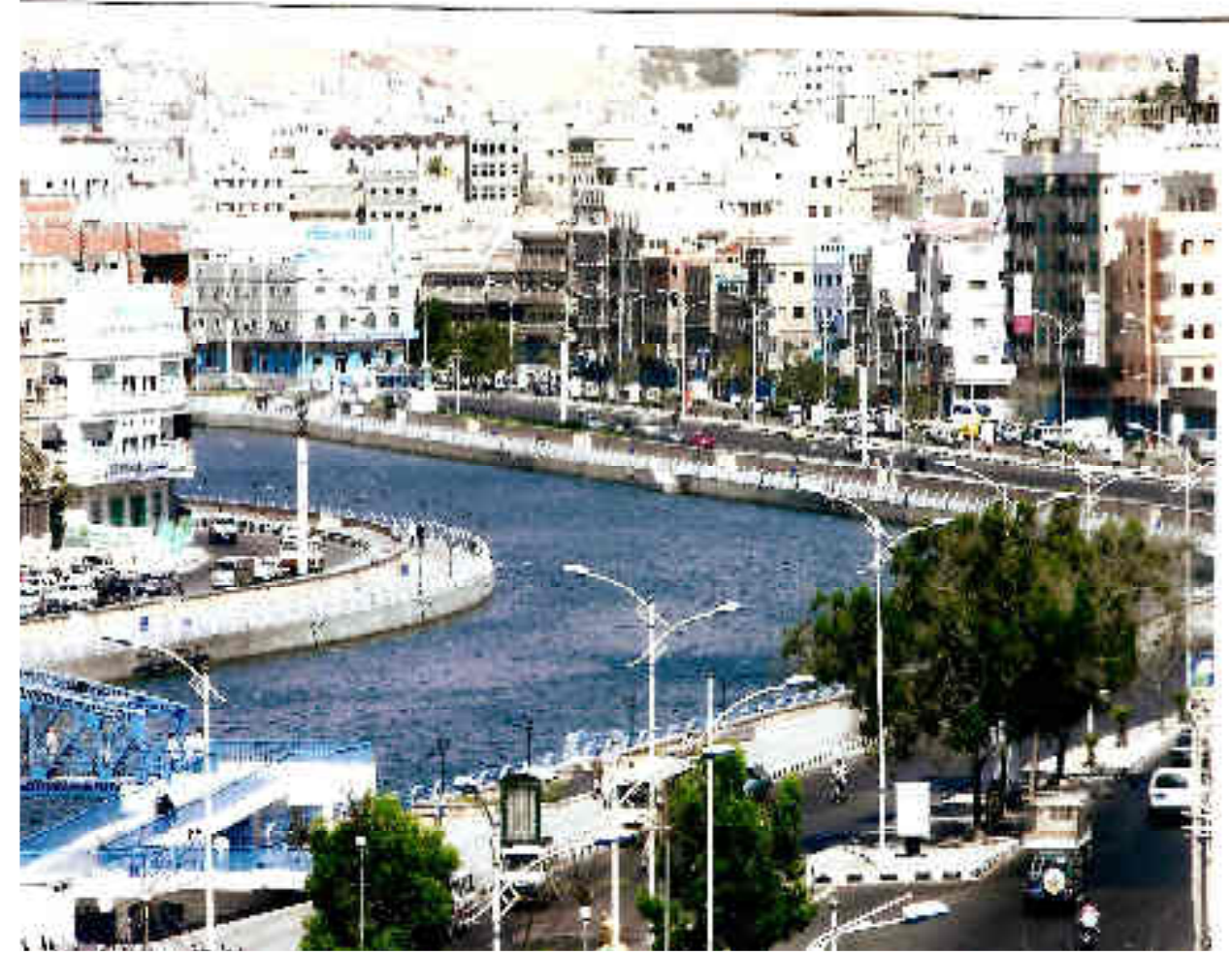

شكل رقم (1) يوضح جاتب من منطقة وسط المدينة والمباني الحديثة التي انثئت بارتفاعات تصل حتى عشرة طوابق ويعضها بمسطحات زجاجية كبيرة.

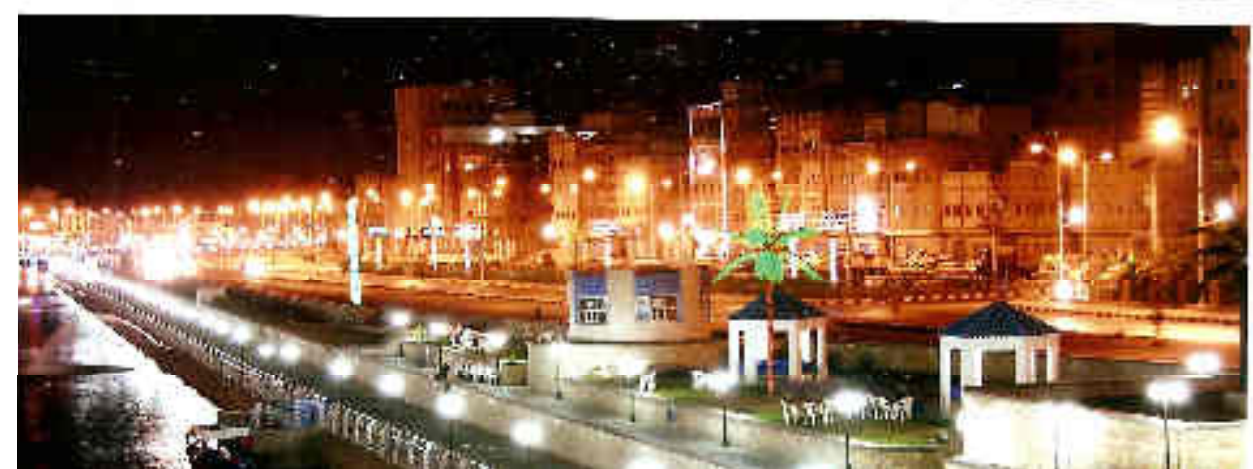


شكل رقم (2) يوضح جانب اخر من منطقة وسط المدينة ليلا ومنطقة الخور (مجرى مياه صناعي من ماء البحر) تم انشاؤة عام 2005 والمباني بارتفاعات مختلفة.

أولا: موقع مدينة المكلا محافظة حضرموت (موقع دراسة الحالة):

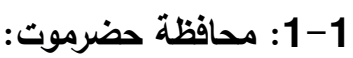

تقع محافظـة حضرموت على ساحل البحر العربي، وتبعد عن العاصمة صنعاء بحوالي (794 كم)، ويشكل سكان المحافظة ما نسبته (5.2\%) من أجمالي سكان الجمهورية، وعدد مديريتها (30) مديرية،

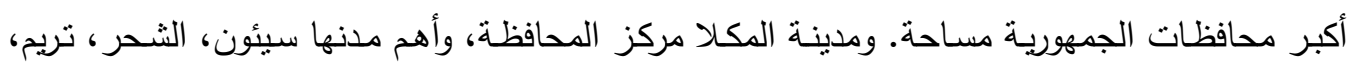
شبام، القطن ومن الأنشطة الرئيسة التي يمارسها سكان المحافظة الزراعة والاصطياد السمكي والثروة

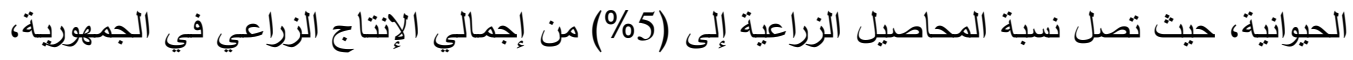

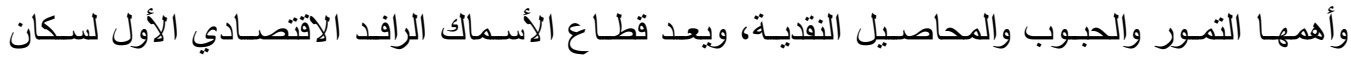

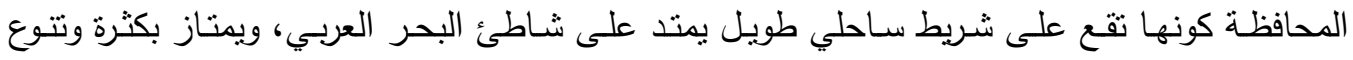
الأسماك والأحياء البحرية، وتضم أراضي المحافظة بعض الثروات المعدنية كنها حقول النفط وموارد معدنية أهمها الذهب. ومن معالم السياحة في محافظة حضرموت المساجد والمدارس ومكتبات مدينة تريم وحصون وحدائق مدينة سيئون وناطحات السحاب في مدينة شبام. وتتميز المحافظة بتتوع مناخها نتيجة مساحتها الكبيرة ويصل منوسط درجة الحرارة خلال أيام السنة إلى (27) درجة مئوية تقريباً [4].

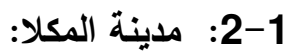

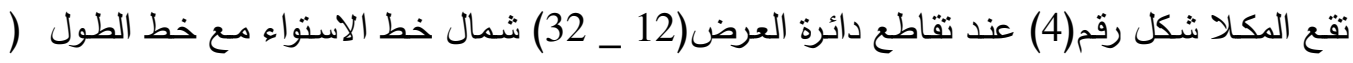

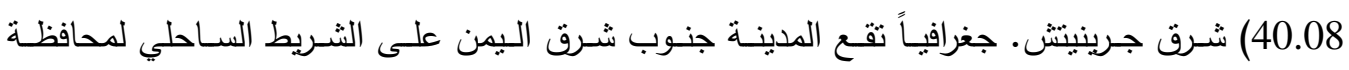


تبعد المكلا عن العاصمة السياسية صنعاء(579م ) وعن العاصمة التجاريـة عدن(620كم) شكل

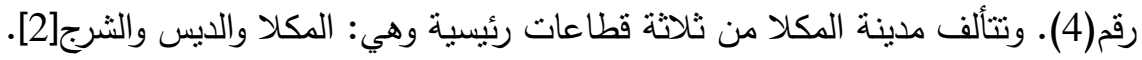

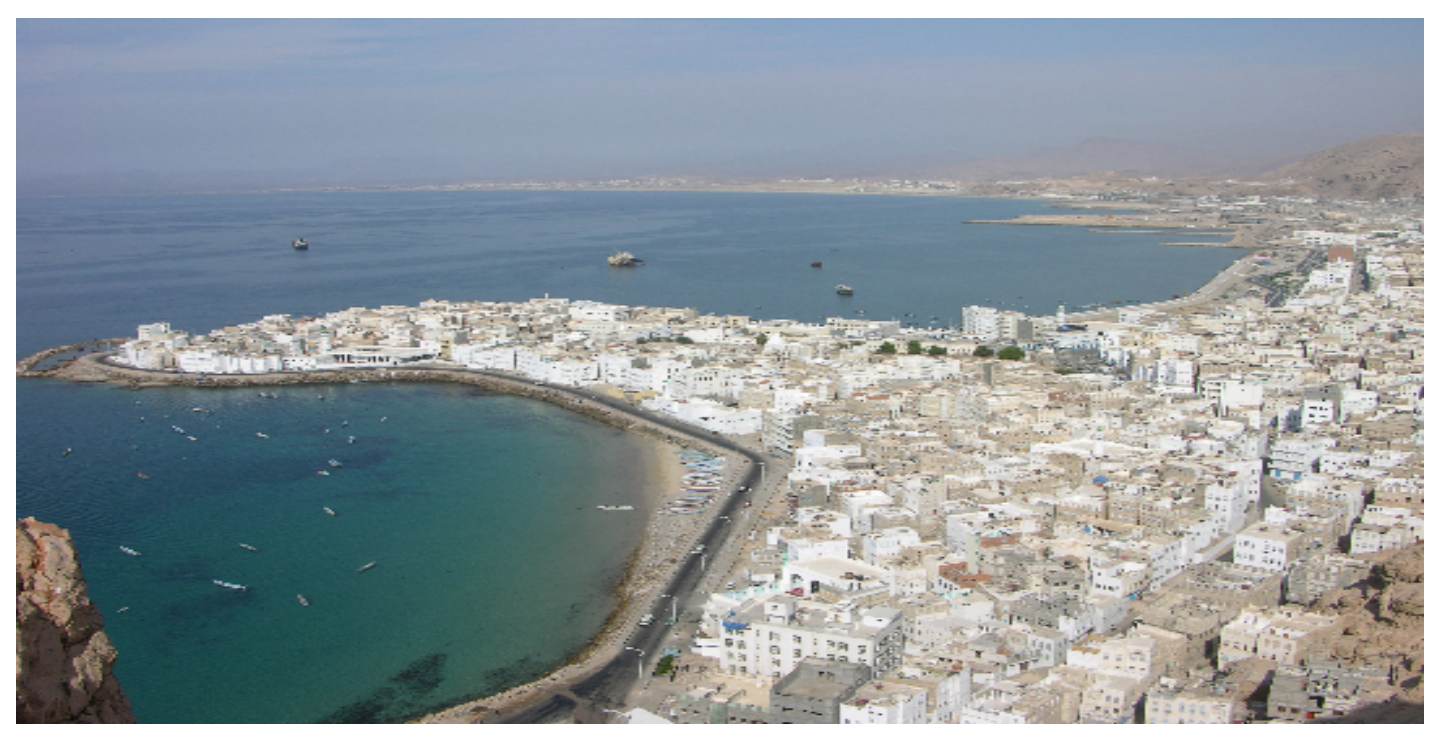

شكل رقم (3) يوضح صورة لمدينة المكلا

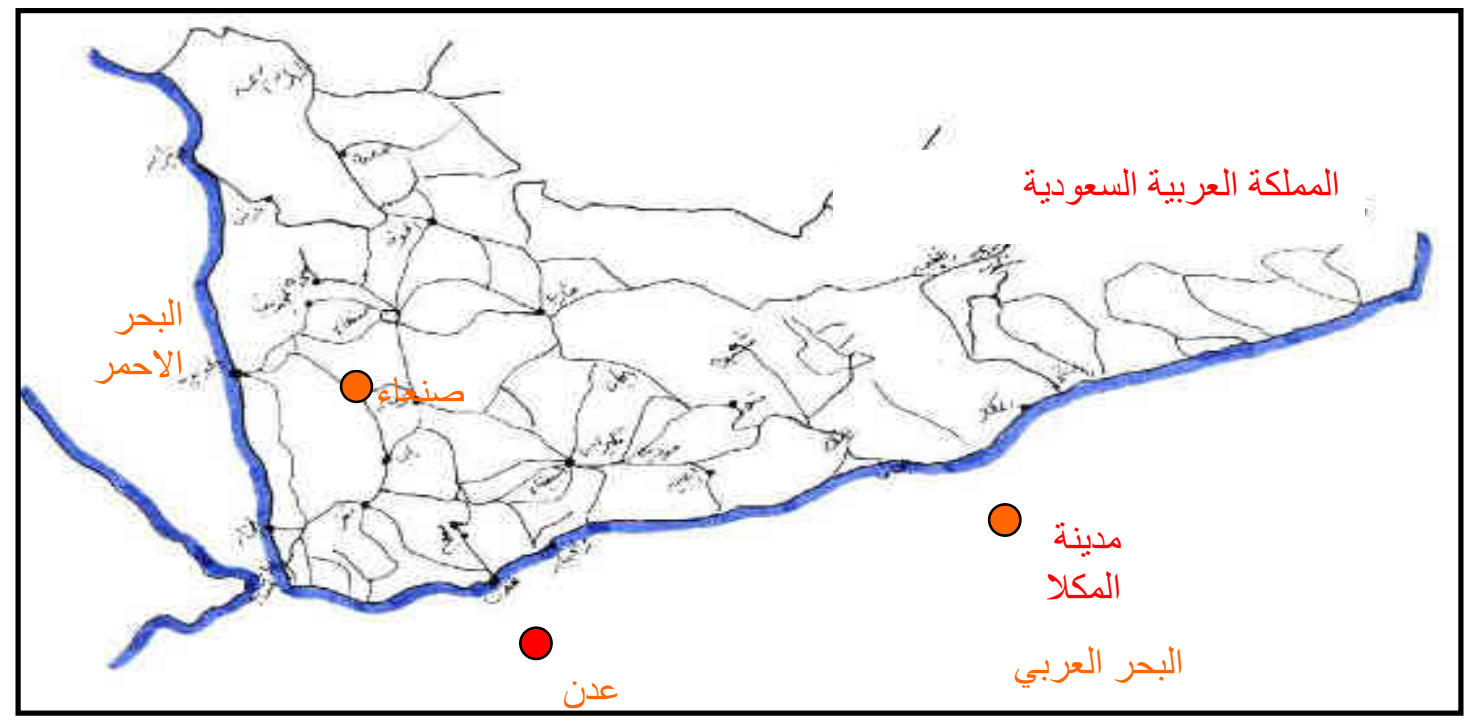

شكل رقم(4) يوضح موقع مدينة المكلا

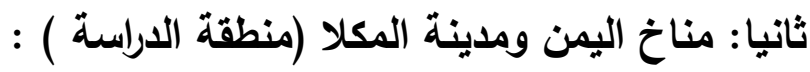

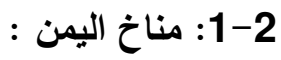


تقع اليمن في المنطقة الحارة وتعتبر من البلدان ذات الإشعاع الثمسي الكبير والطاقة الحرارية العالية

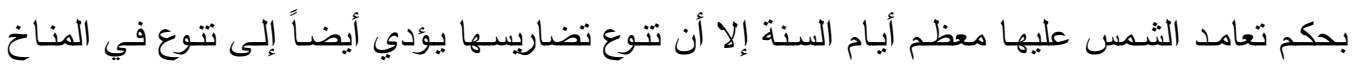
وبتصف المناخ بالآتي : بعامل • في المناطق الساحلية بإرتفاع درجات الحرارة ونسبة الرطوبة صيفاً وبالإعندال شتاءً . أما في المناطق الداخلية والجبلية فيتميز بالإعندال صيفاً والبرودة شتاءً . كما يسود المناخ المعتدل في المنحدرات والهضاب والمسطحات الغربية .

\begin{tabular}{|c|c|c|c|}
\hline الأمطار & 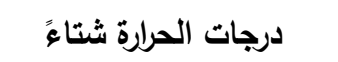 & درجات الحرارة صيفاً & 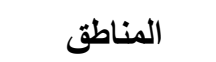 \\
\hline 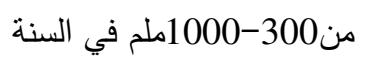 & تتخفض الى مادون الصفر & 10-10-30درجة مئوية & المناطق الغربية \\
\hline 50-50 ملم في السنة & 10-15 درجة مئوية & ت تجاوز 40 درجة مئوية & 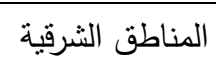 \\
\hline \multicolumn{3}{|c|}{ تقع بين هذين الإقليمين المناخيين من شمال وشرق صنعاء حتى غرب مأرب } & 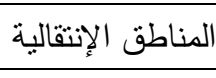 \\
\hline
\end{tabular}

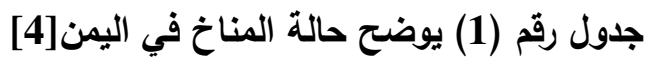

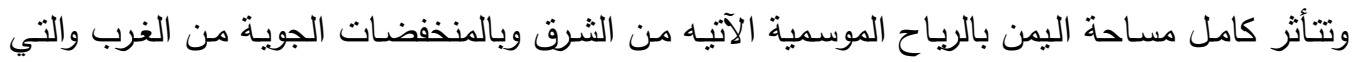
تأتي مصحوبة بالأمطار في موسم الصيف وبكمية أقل في الثتاء .

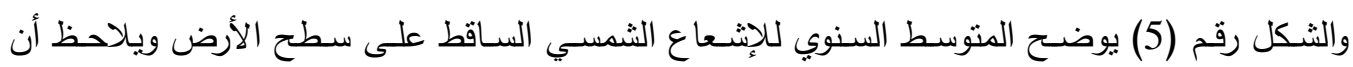

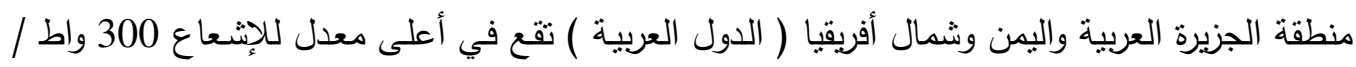

متر مربع [12]

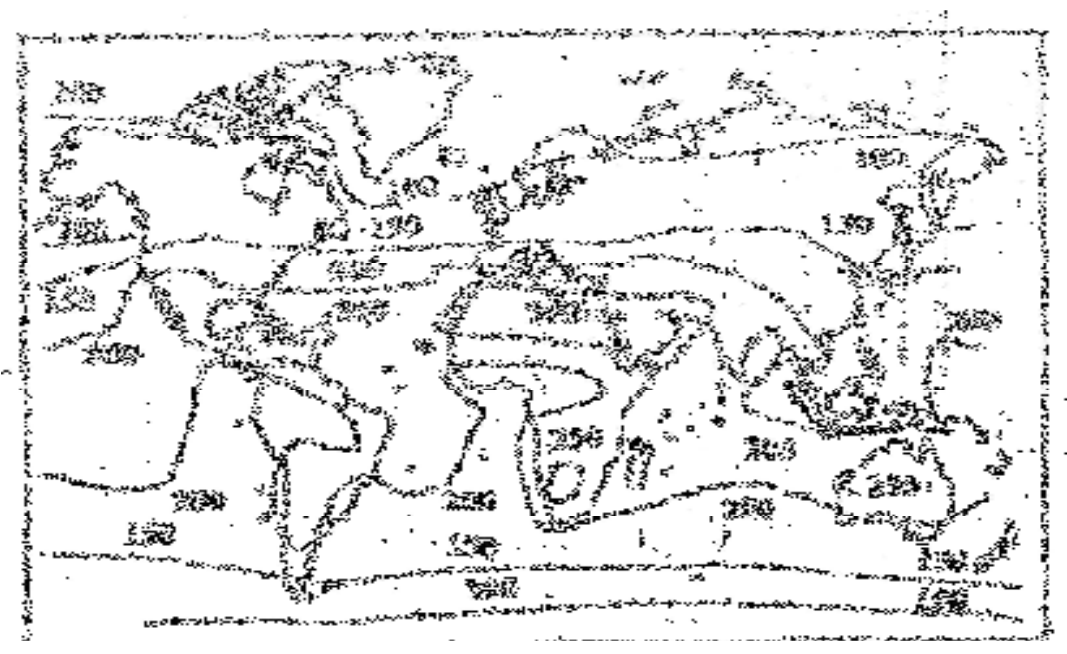

شكل رقم (5) المتوسط السنوي للاشعاع الثمسي الساقط على سطوح افقية على سطح الارض

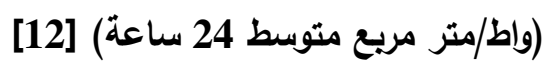

2-2 2-2 مناخ مدينة المكلا : 


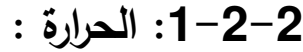

منـاخ حضرموت حـار صيفا في المنطقة السـاحلية ومعتدل في الهضـاب كما تؤثر الريـاح الموسمية الصيفية على تلطيف درجة حرارة المناطق الساحلية حيث تصل درجة الحرارة في المكلا (وهي منطقة

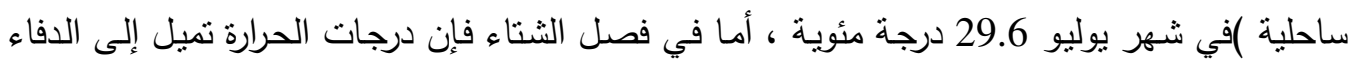

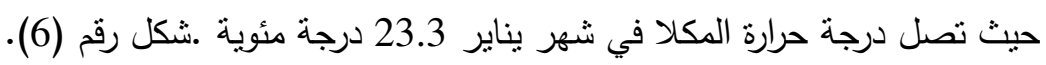

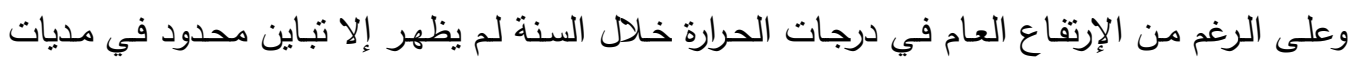
الحرارة اليومية والثهرية والفصلية إذ لا يزيد منوسط المدى الحراري في في مابين أنشهر الصيف واثشهر

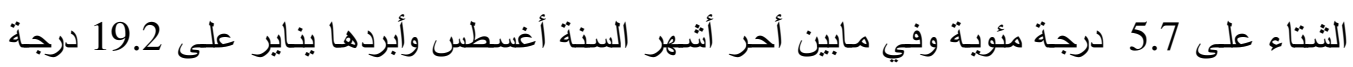
مئوية .

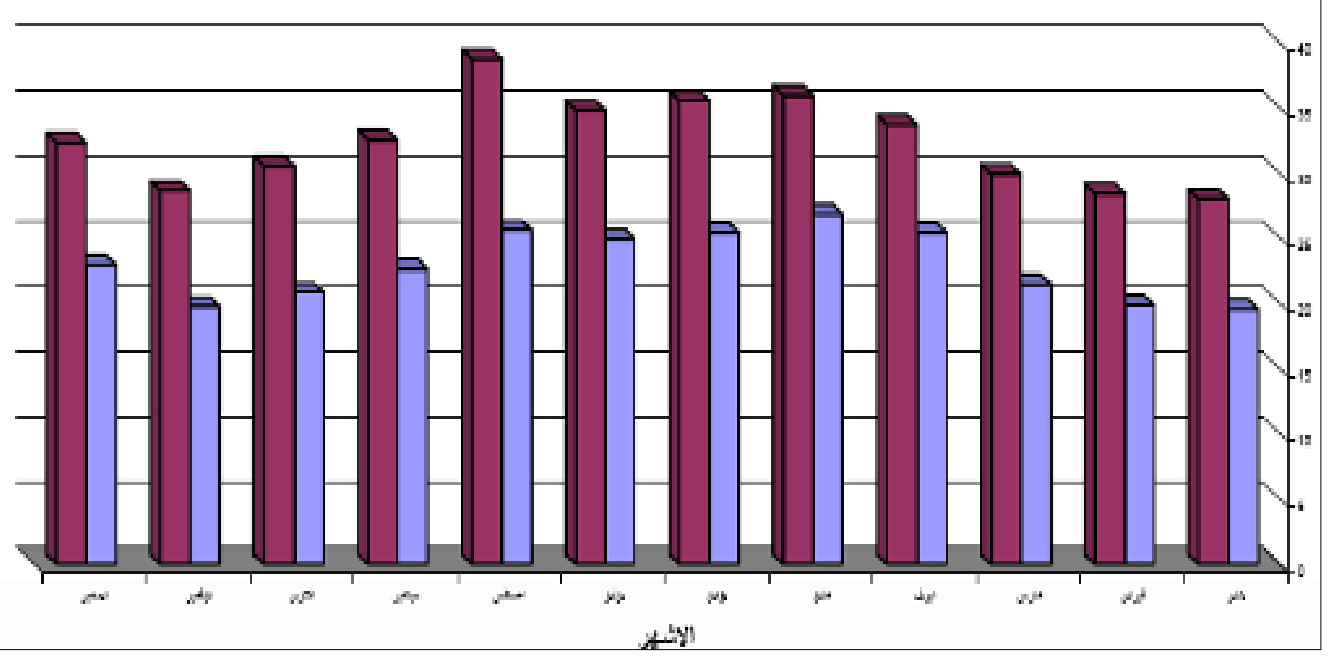

شكل رقم (6) يوضح الرسم البياني لمعدلات درجة الحرارة[1]

وما يسوغ إنخفاض المدى الحراري في المكلا هو قربها من المؤثرات البحرية المتمثلة بنسيم البحر البارد

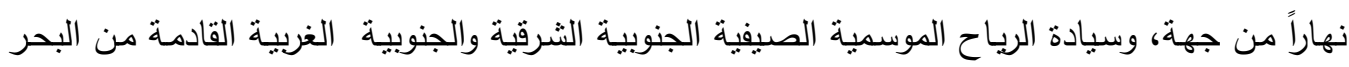
العربي والمحيط الهندي والحاملة معها صفات الرطوبة النسبية من جهة أخرى.

2-2-2

تتصف المكلا بارتفاع الرطوبة النسبية إذ تتراوح معدلاتها العظمى بين( 96.92\%) ومعدلها السنوي

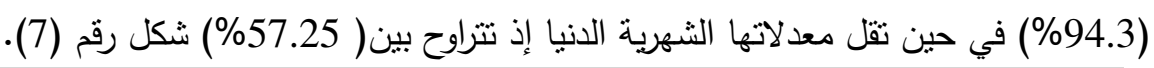

ב


شكل رقم (7) يوضح الرسم البياني لمعدلات الرطوبه النسبية [1]

2-2

إن الإثعاع الحراري هو عبارة عن موجات كهرومغناطيسية نولدها الحركة الحراريـة للجزيئات المكونـة

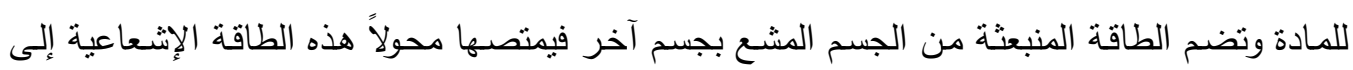

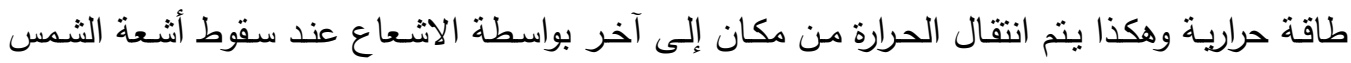
المباشرة على سطح غير منفذ للأشعاع ، وقد يتم إمتصاص هذه الأشعة بواسطة السطح أو ينم انعكاسها

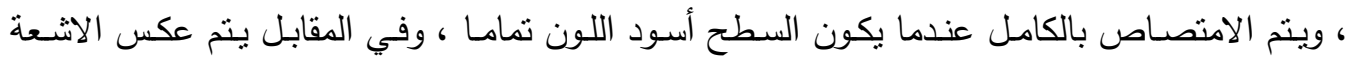

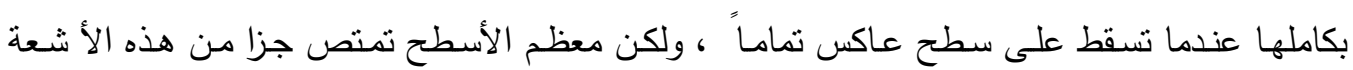
وتعكس الجزء الاخر أنظر الثكل رقم (8) [6].

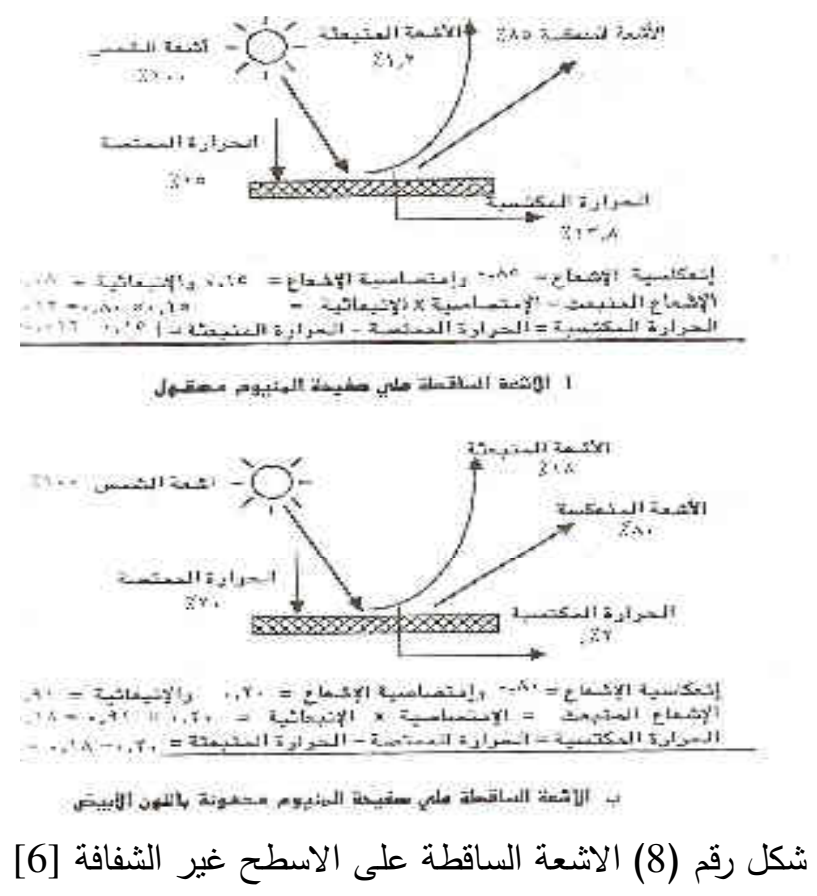


كما يؤثر على عملية امتصاص أو أنعكاس الأشعة الحرارية نوع مادة البناء ونوع الأسطح والتشطيبات

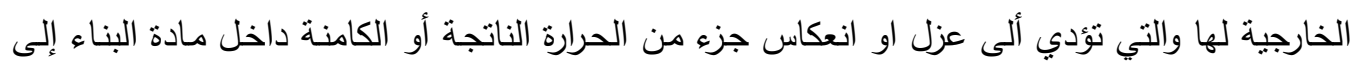

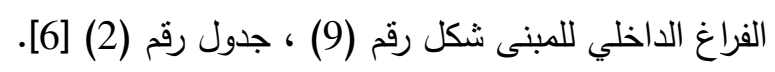

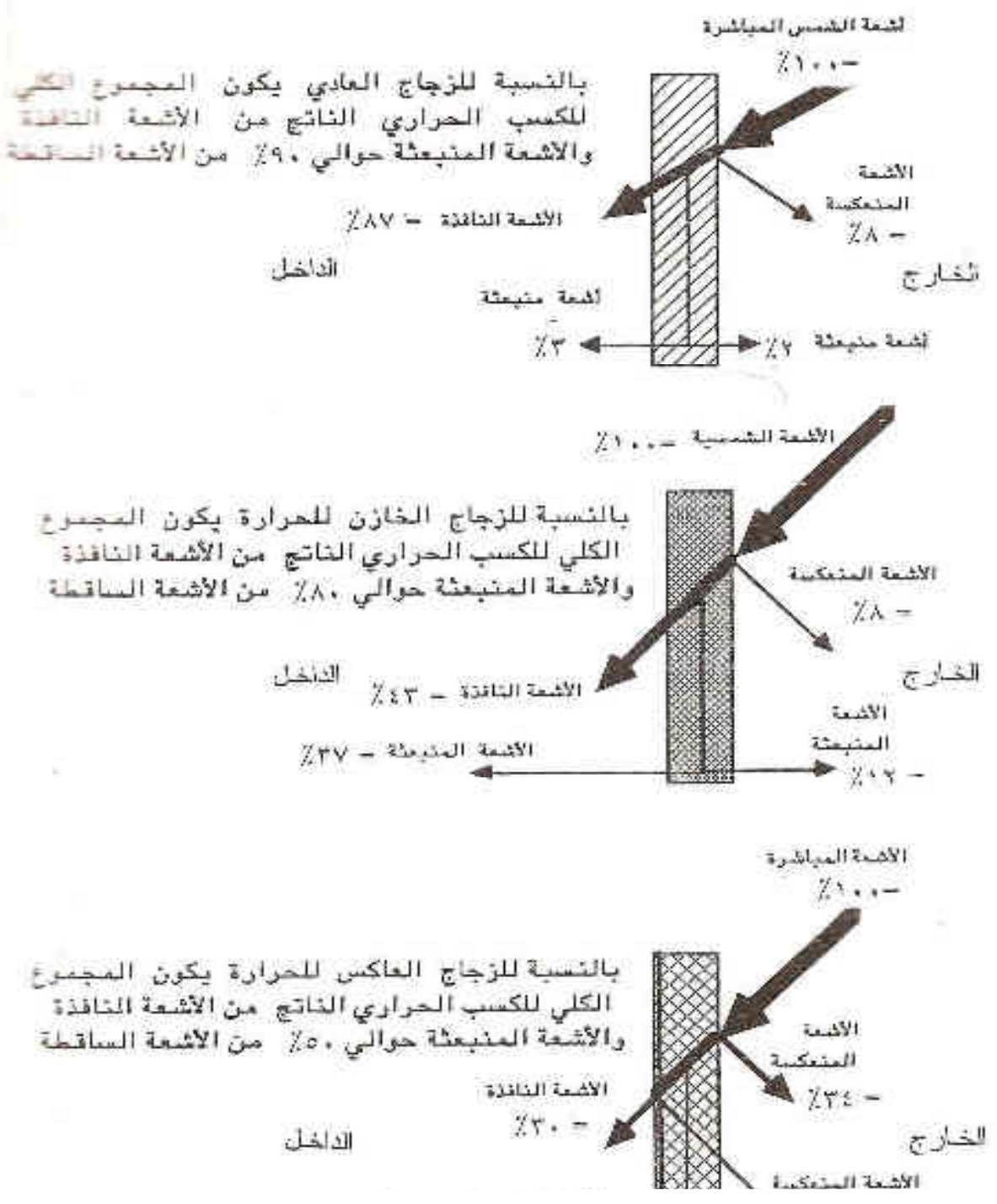

شكل رقم (9) نفاذ الاشعة خلال المسطحات الزجاجية والتي تؤكد على قوة النفادية لاشعة الثمس من

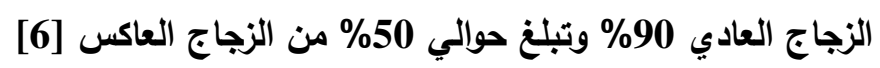




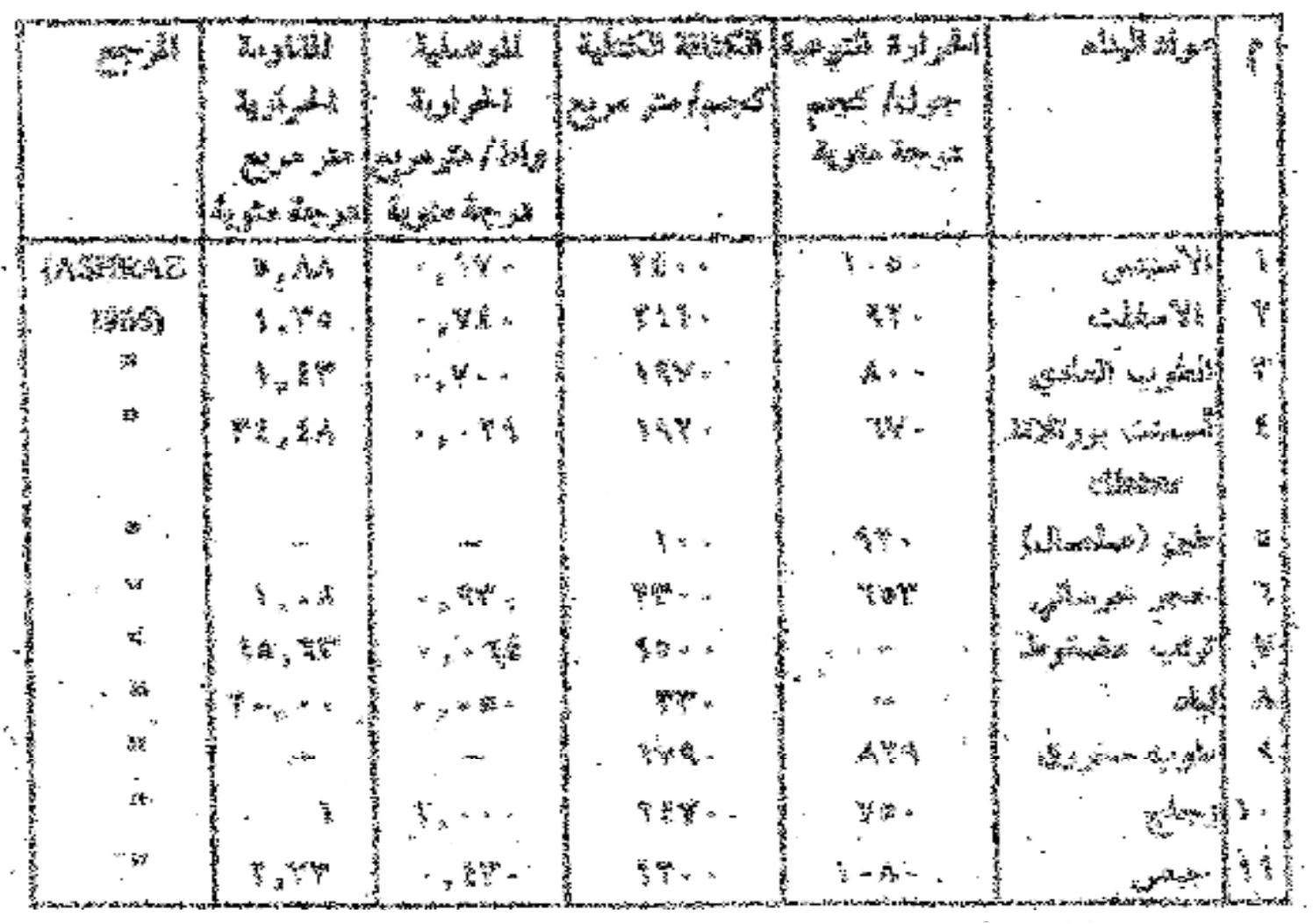

للطوب العادي 43،1 للاسبستس 88،5 وللزجاج الموصلية الحرارية1 [6]

\section{ثالثا : الأسس التصميمية للمباني للمناطق الحارة :}

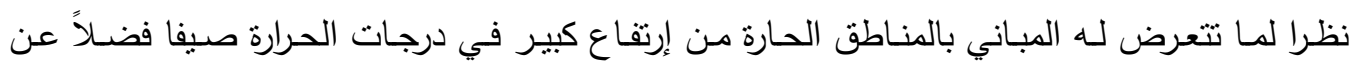

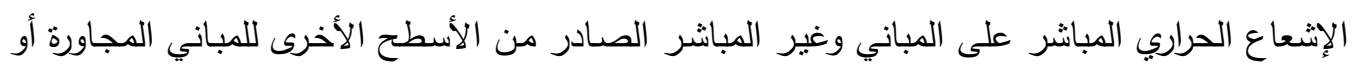

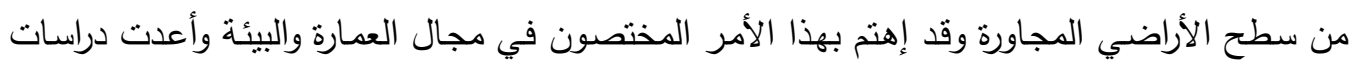

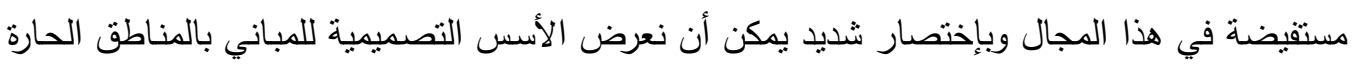

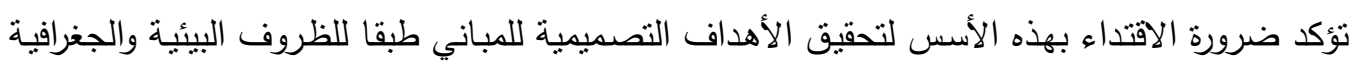

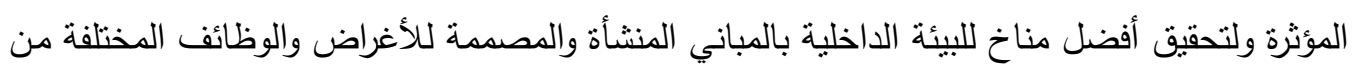

$$
\begin{aligned}
& \text { سكنية وإدارية وخدمية وتعليمية وصحية .. الخ وذللك فيما يلي :- }
\end{aligned}
$$

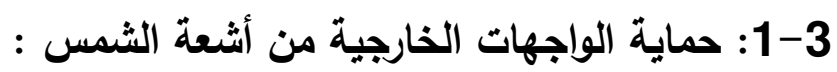

تعتبر من أهم الأسس التصميمية للمباني ، ان يتحقق فيها حماية واجهاتها من الأثعة الثمسية المباشرة الثبه

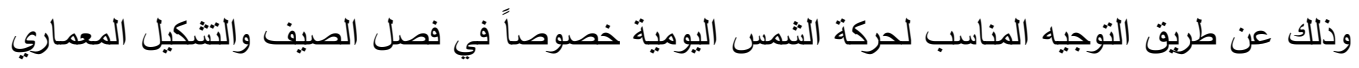
لكتل المبانى بما يحقق نسبة معقولة من النظليل للواجهات على بعضها البعض وإستخدام البيئة الخارجية 
والنتجير والمساحات الخضراء لزيادة النظليل والتخفيف من الأشعاع الثمسي الغير مباشر على واجهات

\section{3-2:3: استخدام مواد البناء المناسبة :}

لاثكك أن مواد البناء لها دور فعال في تحقيق تخفيض الإثعاع الحراري داخل المباني .. ففي العصر الحديث تتوعت وتعددت مواد البناء بثكل ملحوظ سواء في خاماتها وتشكيلاتها وإستخداماتها مما جعلها لهاريا

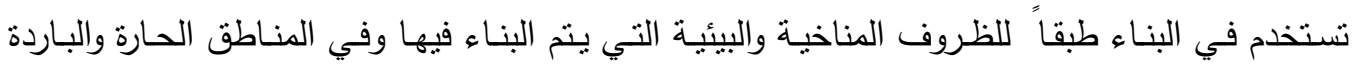
وتهدف إلى تحقيق الراحة الحرارية داخل تلك المباني ...كذلك فان سماكة الحوائط الخارجية لها تأثير

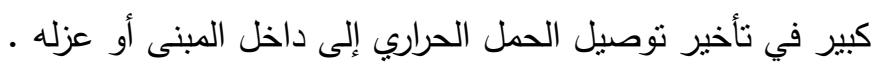

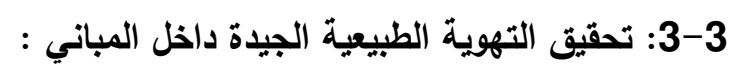

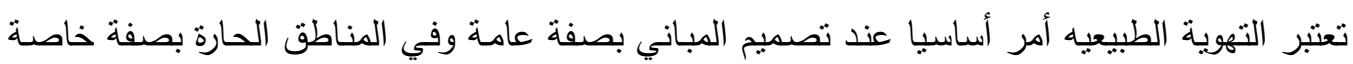

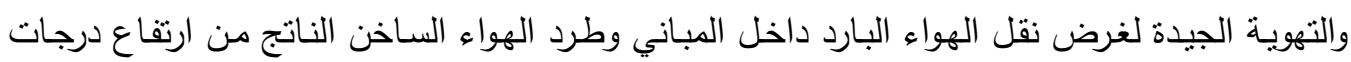

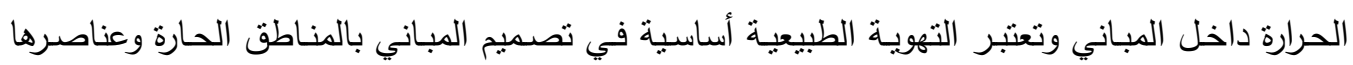

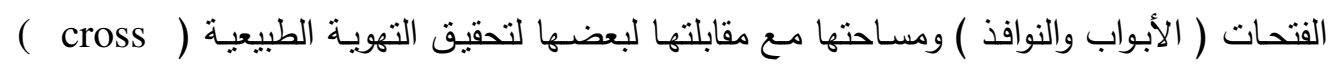
ventilation

\section{3-4: استخدام الأفنية الداخلية :}

استخدام الأفنية الداخلية التي تحقق التهوية الجيدة والفضاء الداخلي المزود بالمساحات الخضراء ونوافير

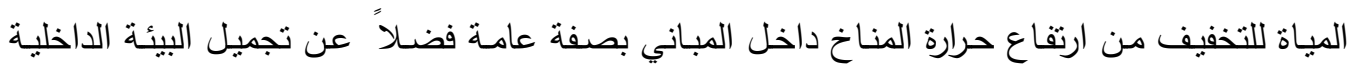
للمباني - لمياة

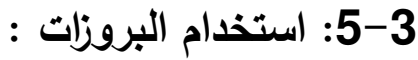

استخدام البروزات للخارج بالثكل المناسب لتحقيق التظليل والتخفيف من الأشعاع المباشر لأشعة الثمس على أسطح وواجهات المباني (كاسرات الثمس). 3-6 إستخدام الممرات المظللة خارجية وداخلية ودورها الفعال في التخفيف من شدة الحرارة وسقوط أثعة الثمس على المباني وبالتالي حماية الفضاءات الداخلية لعناصر المبنى من ارتفاع درجات الحرارة بها. 


\section{4-1 المعالجات البيئية في اليمن:}

4-1-1-1 العمارة اليمنية التقليدية:

تتفرد المدن اليمنية عموماً بخصوصية تميزها عن المدن الإسلامية، فهي حصيلة الخبرات الجمة للآباء

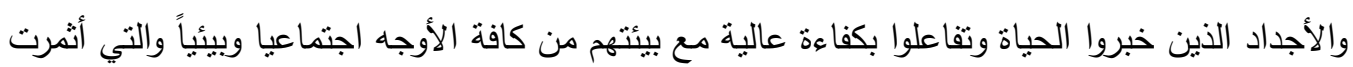

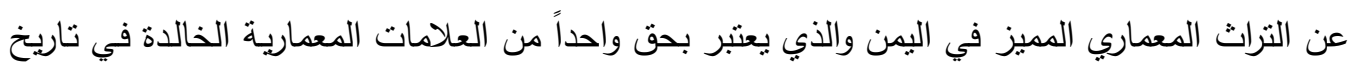
العمارة.

وأهم الخصائص البيئية للمدن اليمنية هي كالتالي: 1. المنزل البرجي (تعدد الطوابق). 2. - 2 - القمرية. 3. ت نتوع وتعدد الفتحات.

4. الثوارع الضيقة والتي تسمح بمرور الهواء خلالها. 5. إطلالة واجهات المباني الخلفية على حدائق صغيرة. 1-4-2-1 مدينة صنعاء القديمة:

إن مدينة صنعاء القديمة شكل رقم (10) تعتبر من أهم المدن اليمنية التي ممكن أن نضعهاء أحد الأمتلة

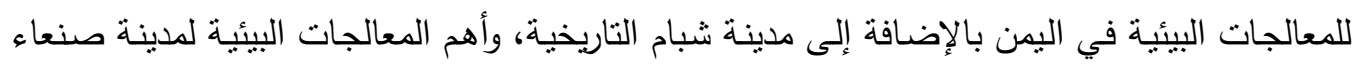
القديمة كالتالي:

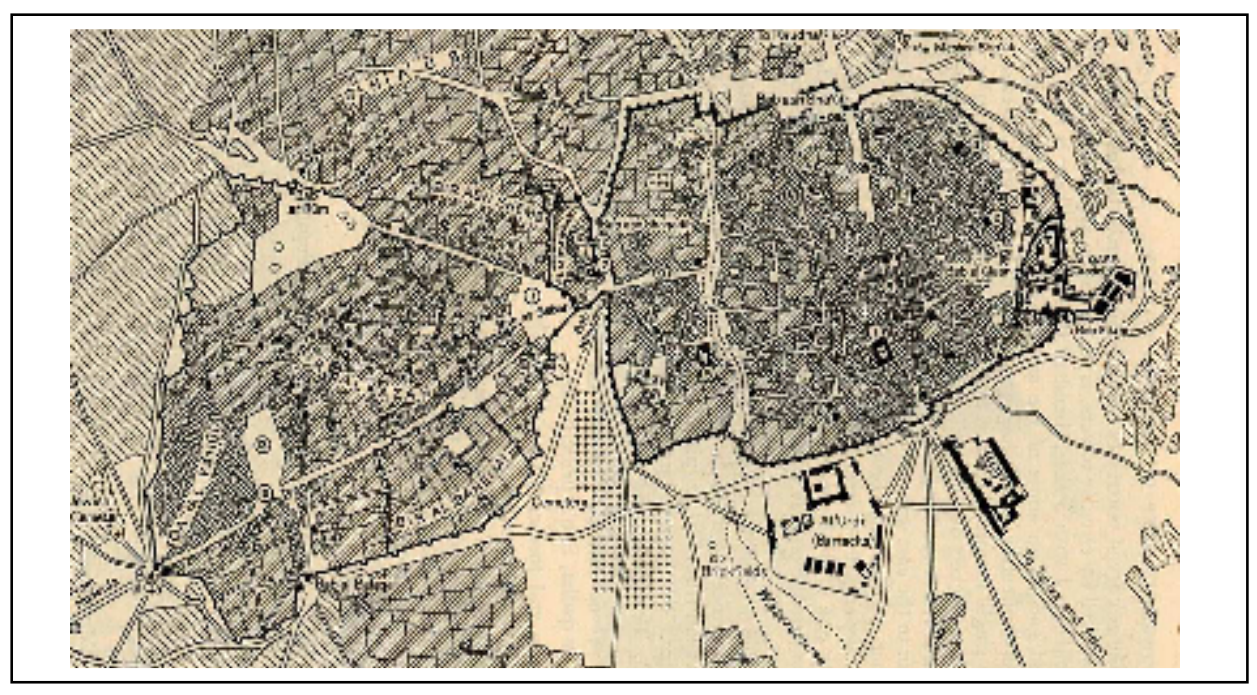

شكل رقم (10) يوضح مدينة صنعاء القديمة

أ ـ تجمع الكتل حول الأفنية: 
تميز المسكن والذي تميز بالارتفاع وضيق رقعة الأرض التي يشغلها والذي ينت تجمعه حول فراغات وحدائق عامة، يظهر مدى الخصوصية والتميز التي تتمتع بها مثل هذه المدينة العريقة.

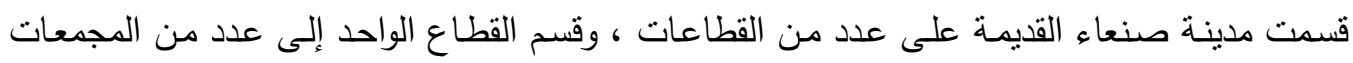

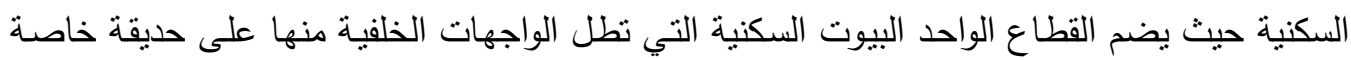

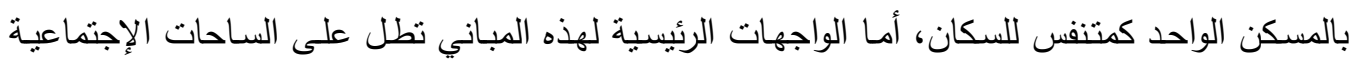

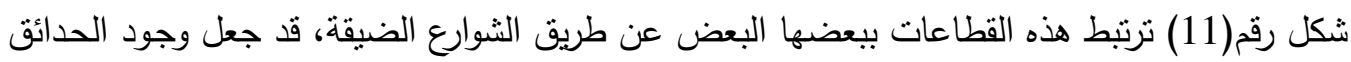
أو المزارع والساحات الإجتماعية في وسط هذة التجمعات إلى جانب الطرقات والأزقة أساسيا وضرورياً

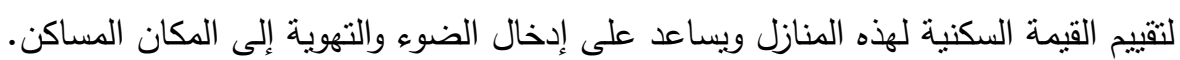
ثم يأتي بعد ذلك المسجد الذي يعتبر من سمات المدينة اليمنية وباقي المدن العربية ، ثم بتعدد وظائفها

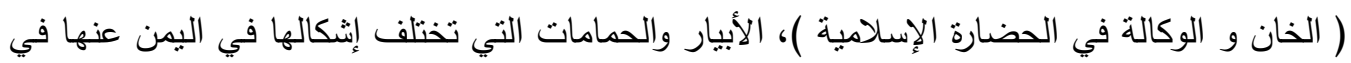
المدن العربية ، ثم الأسواق المفتوحة والمغلقة وربما كانت أكثر شيوعاً في صنعاء لاعنداء الاعدال المناخ شكل

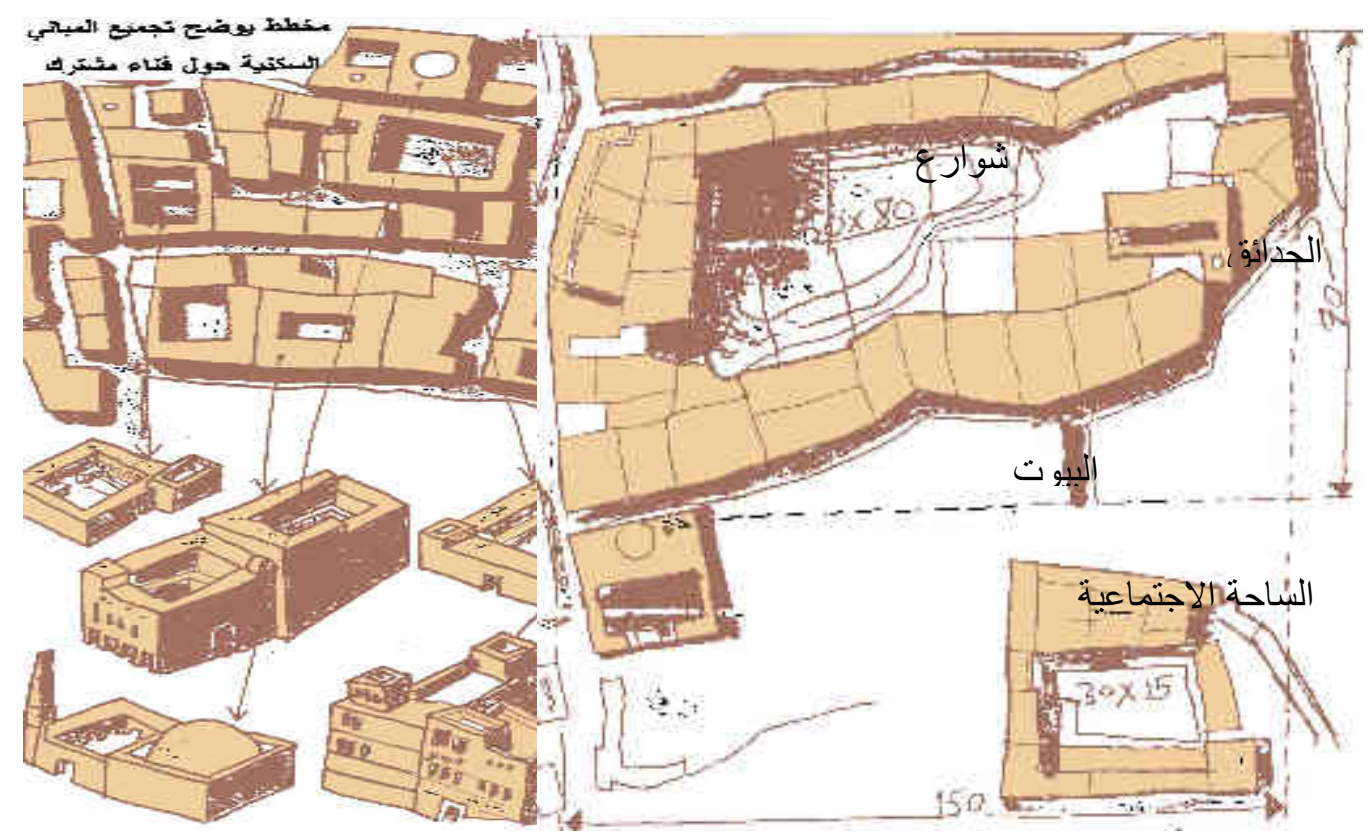

شكل رقم(12) يوضح تجمع الكتل حول أفنية وتوضح الأسواق إق إق إق

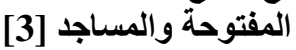

شكل رقم(11) يوضح القطاع السكني الواحد [3 [3ينة صنعاء السكنية

ب ـ الإتجاه الرأسي للمباني(تعدد الطوابق): 
نلاحظ أن الاتجاة الرأسي للبيت اليمني شكل رقم (13) وإعتمـاده المباشر على الاتجاهات التي تتبع

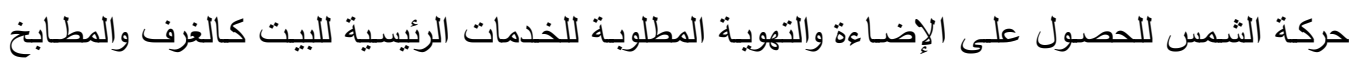
والحمامات والأدراج. حيث كان التجمع السكاني يعتمد على إستقلالية صحن البيت باعتباره فراغاً خاصاً ، وهو ما لا يلبي الوظيفة الاجتماعية الخصوصية (والتي عولجت بالبيئة اليمنية باسلوب متميز) .
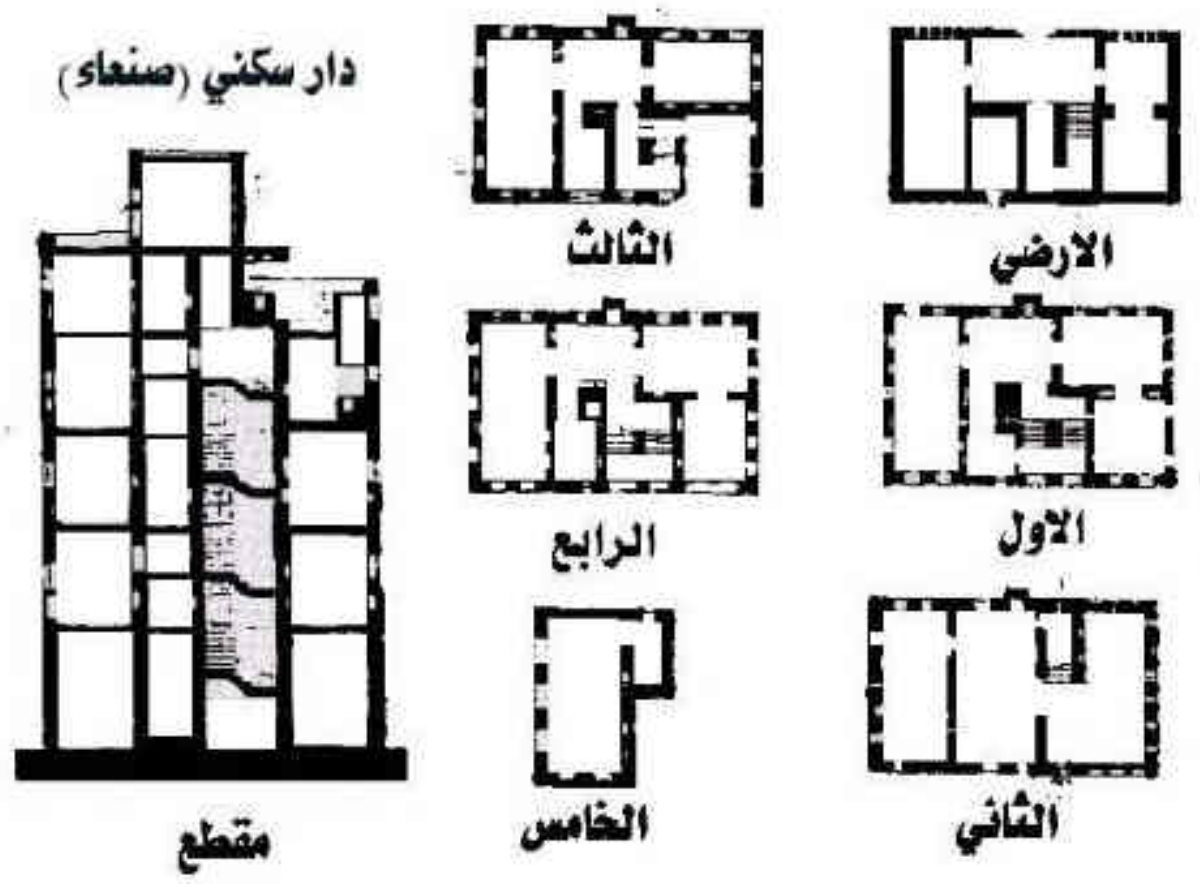

شكل رقم (13) يوضح الإتجاه الرأسي للمباني (تعدد الطوابق) بمدينة صنعاء وفتحات التهوية لاموجوده

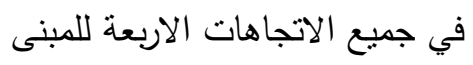

\section{جـ ـ المعالجات على الواجهات: 1. 1 إستخدام القمرية:}

الوظيفة الأساسية للقمريـة هي إدخال الضـوء الطبيعي إلى داخل الفضـاء، علاوة على إضفاء مسحة

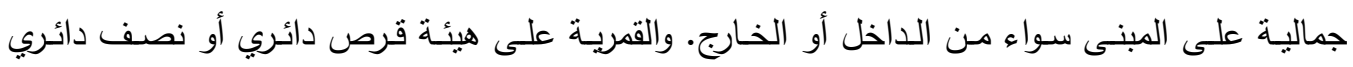
مصنوعة من حجر الألباستر سمك (0.1م) شكل رقم(14). ويعود السبب في تسميتها بالقمرية لبياضها

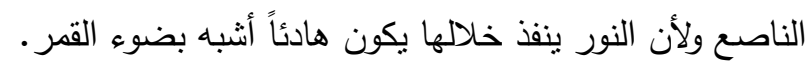




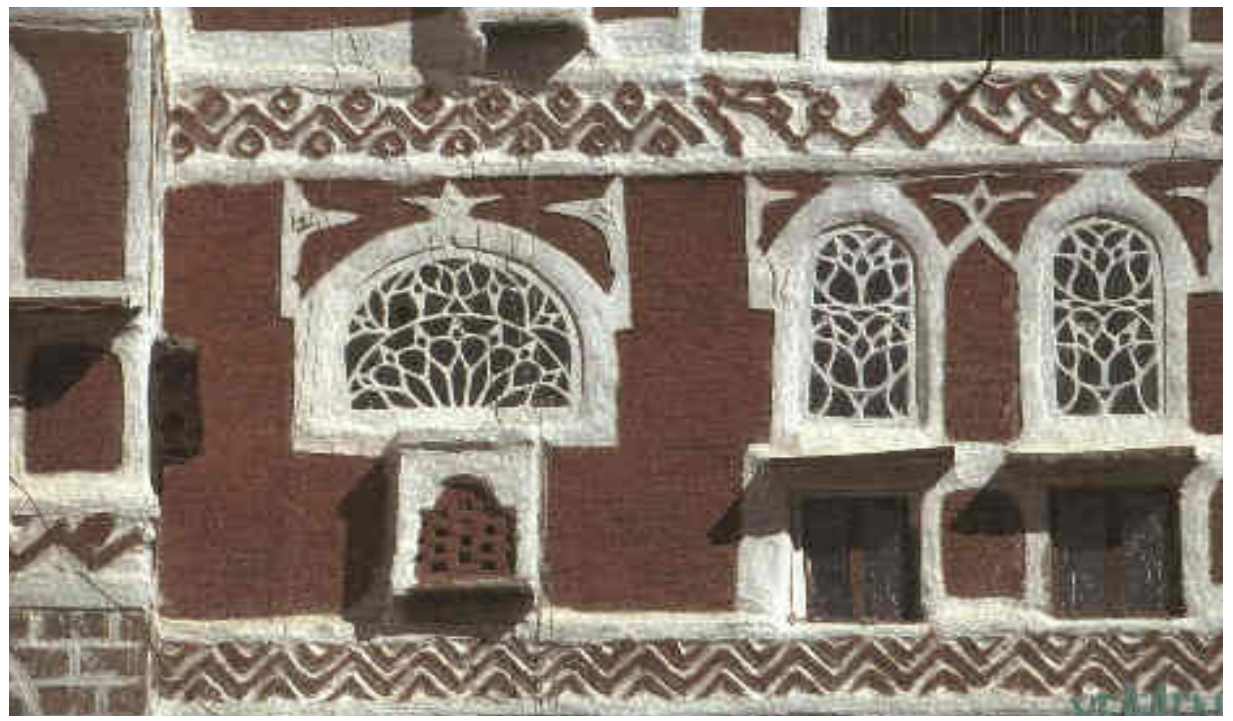

شكل رقم(14) يوضح القمرية فوق النوافذ وتقاصيل الزخرفة بالواجهات

\section{2. تتوع وتعدد الفتحات:}

تتميز الفتحات في صنعاء بانها صغيرة في الأدوار السفلى وتزداد إنساعاً في الأدوار العليا، وتتكون النافذة من خمسة عناصر وهي: أ) الجزء العلوي (القمرية).

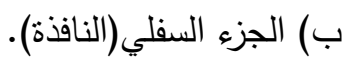

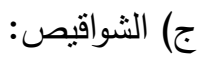
تقع عادة بين النوافذ مع الجزء العلوي ووظيفتها تفىء بالتهوية وعادة يكون أبعادها (0.2×0.5م). د) الكنة:

تقع في مكان منوسط بين الجزء العلوي والجزء السفلي وتصنع من الخشب عرضها أكبر قليلا ضمن النافذة وبروزها حوالي (0.25م) ووظيفتها حجب أشتعة الثمس المباشرة من الدخول الى الفضاء الداخلي.

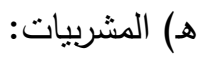

غالباً تصنع من الخشب واحياناً من الجبس والفائدة منها هي لتهوية الفضاء بدون إضـاءة شديدة وحفظ الخصوصية شكل رقم(15). 
شكل رقم(15) يوضح عناصر النافذة الخمسة( القمرية وتفاصيلها، النوافذ، الثواقيص، الكنة، المشربية)

\section{د ـ معالجة أسطح المباني (زراعة أسطح المباني):}

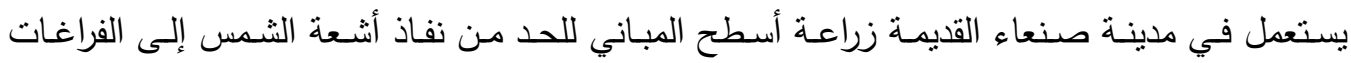

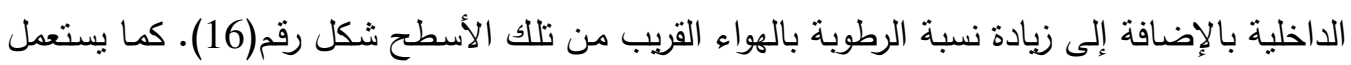
للغرف العلوية فتحات في السقف للتهوية[3].
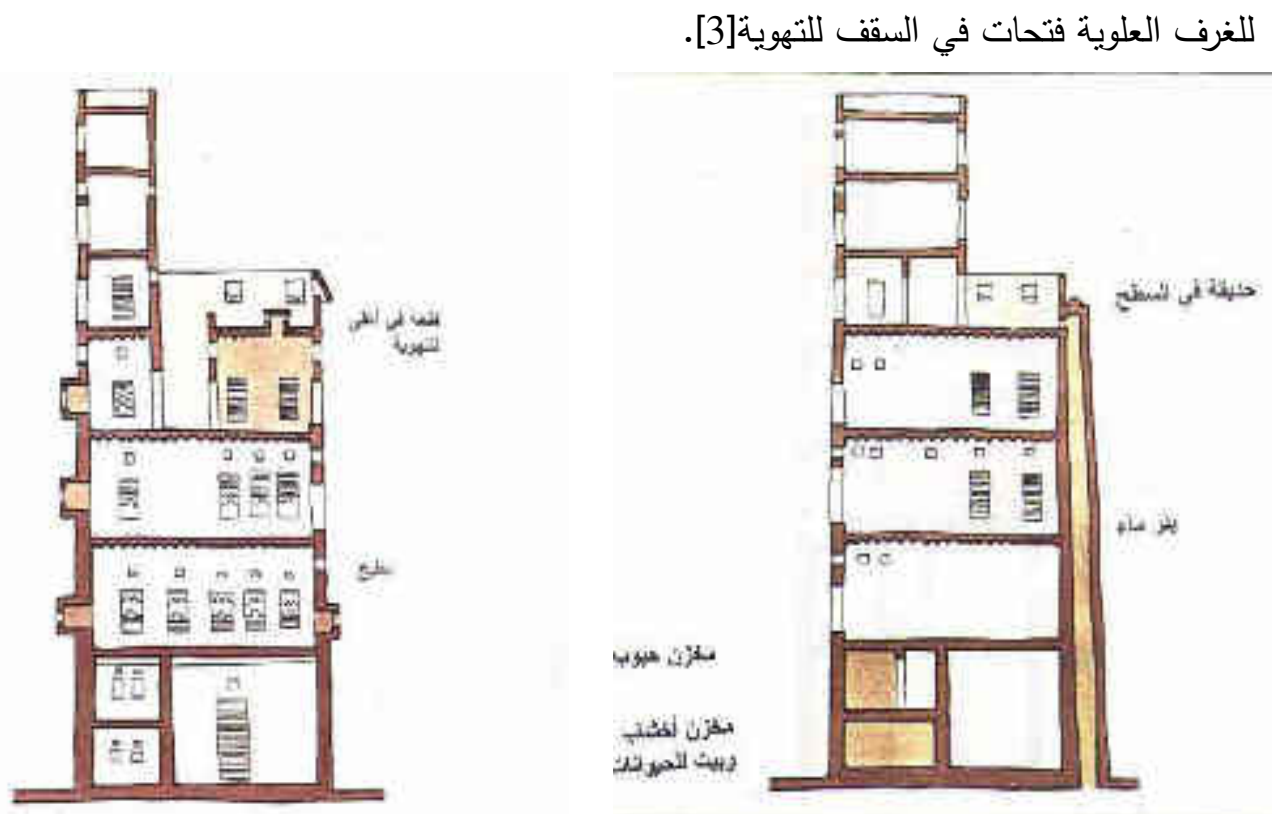

شكل رقم(16) يوضح زراعة أسطح المباني والفتحات العلوية للتهوية

4-2: دراسة حالة المباني في مدينة المكلا والمعالجات المعمارية والبيئية بها: ونعرض فيما يلي بعض الأمثلة للمباني المميزة بيئياً:4-2-1 مبنى الإدارة المحلية بمدينة المكلا:

من مباني مدينة المكلا التي يمكن أن تؤخذ بنظر الإعتبار هي المباني القديمة التي بنيت في مدينة

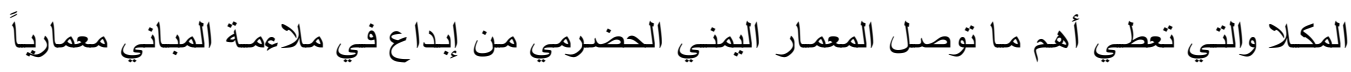


وبيئياً بحيث تتلاءم مع المناخ الحار الرطب بمدينة المكلا ويشعر الإنسان في داخلها براحة حراريةشكل

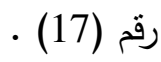

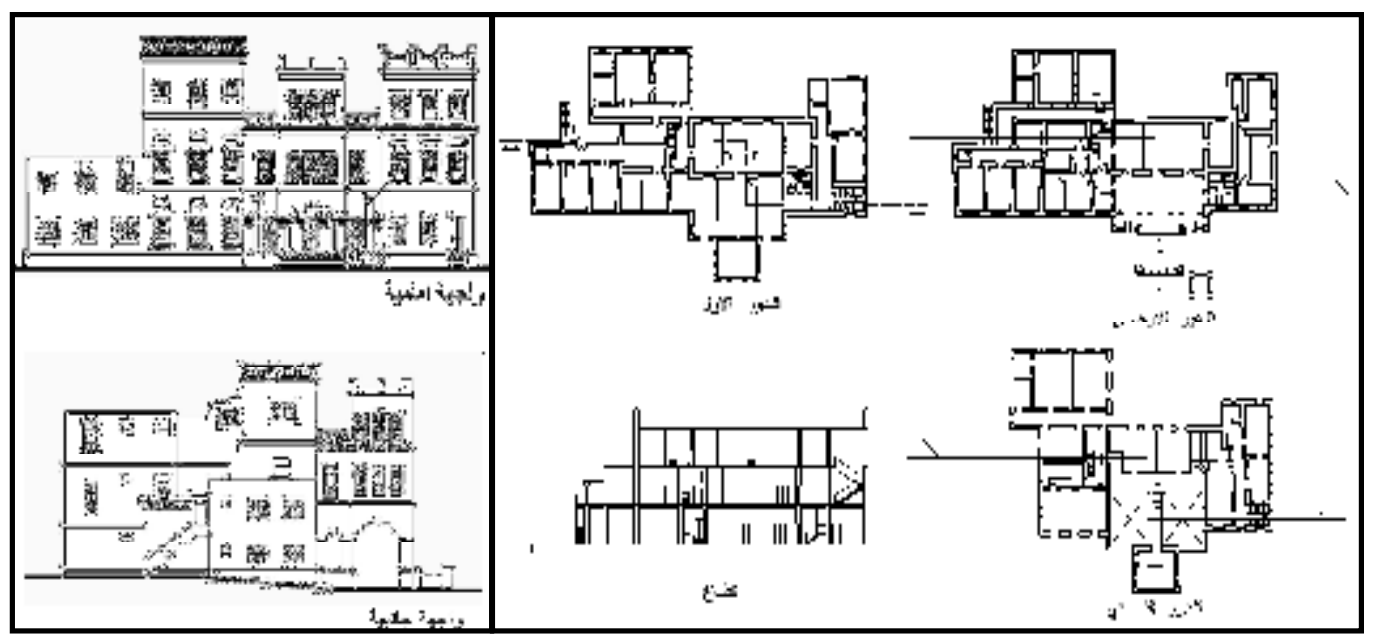

شكل رقم(17) يوضح مساقط أفقية وقطاع وواجهات لمبنى الإدارة المحلية بمدينة المكلا

\section{4-2-2 نموذج بيت سكني بمدينة المكلا:}

نتيجة لضيق المساحة البنائية في مدينة المكلا أضطر أهلها إلى التوسع الرأسي لمبانيهم وعدم استخدام

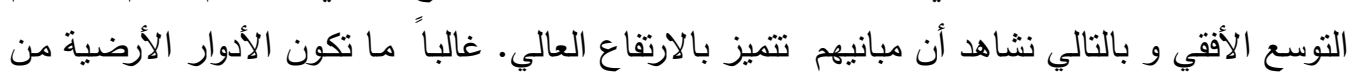

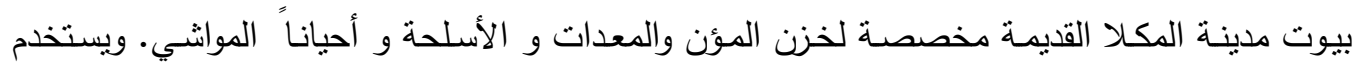
الدور الأول لاستقبال الرجال و جلوسهم.و الدور الثاني للنساء و جلوس العائلة ولتناول طعامهم أيضاً

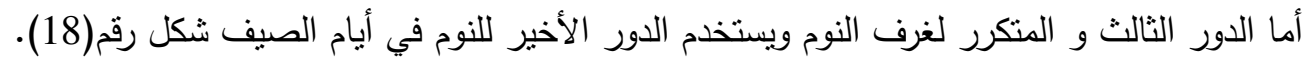
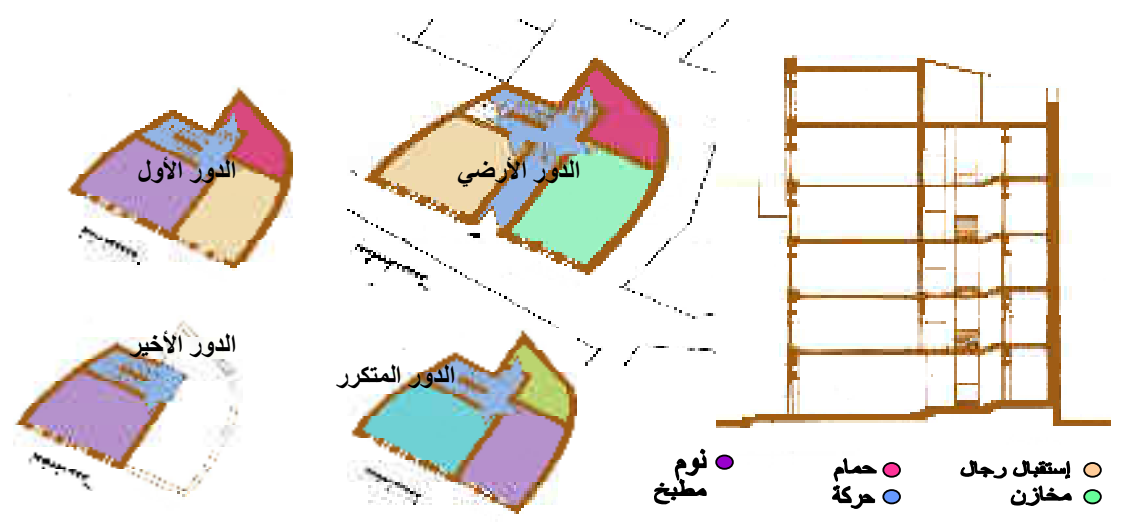

شكل رقم(18) يوضح مساقط وقطاع لبيت سكني بمدينة المكلا

4-3 المعالجات المعمارية والبيئية للمباني بمدينة المكلا: 
4-3-1-3 معالجة القتحات والثبابيك:

أسلوب الفتحات والثبابيك المستخدم في مدينة المكلا يعتبر من أحد اهم المعالجات المناخية للمناطق الحارة الرطبة، حيث تساعد على التقليل من أثتعة الثمس وتتحكم بكمية الضوء النافذ الى داخل الفضاء

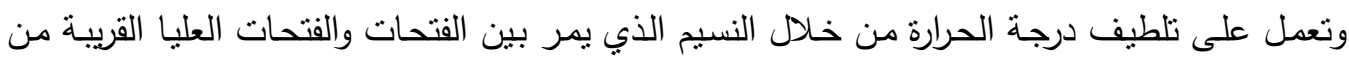
السقف.

الثبابيك في مدينة المكلا فتتكون من جزئين: الجزء السفلي وهو عبارة عن مشبكات ذات أنثكال هندية

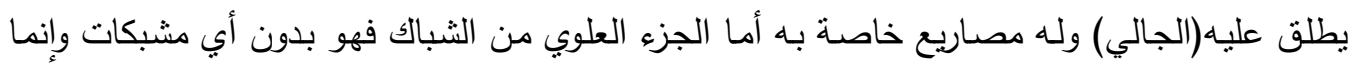

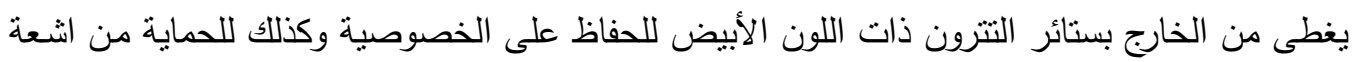

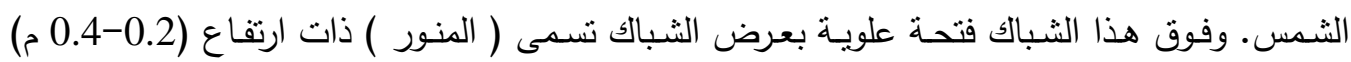

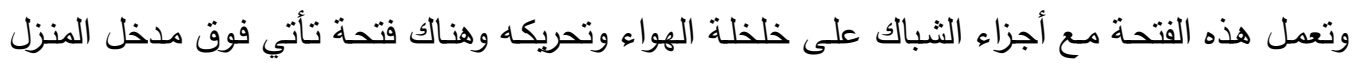

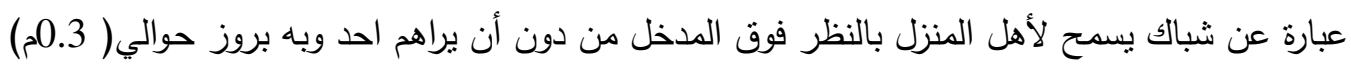

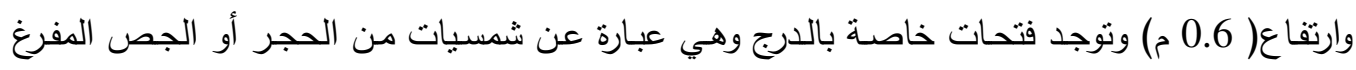
بزخارف هندسية ونباتية. أما أبعاد الثباك التقليدي في ساحل حضرموت (0.75 - 0.90م) العرض أما الارتفاع (1.40-1.60 م)

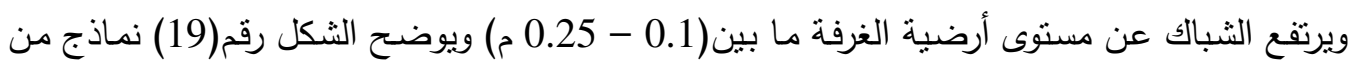
الفتحات والثبابيك التقليدية في مدينة المكلا.

\section{(1-3-4 معالجة الحوائط:}

أ - الحوائط وعروضها ومواد بنائها:

استعمال مادة الحجر في البناء سمك الجدار يتراوح ما بين (0.4-0.5م) شكل رقم(19،18) و التي توجد التهد

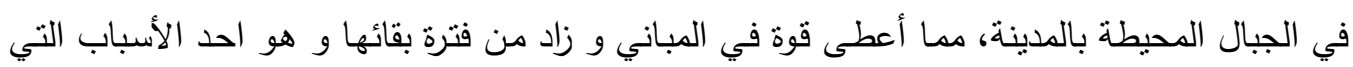

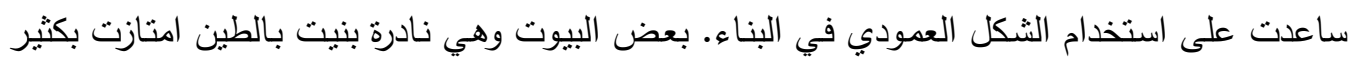
من الصفات التي نوافق مناخ المنطقة، والتي استطاعت من خلالها خلق إبداع في التصميم و خاصة التهاه

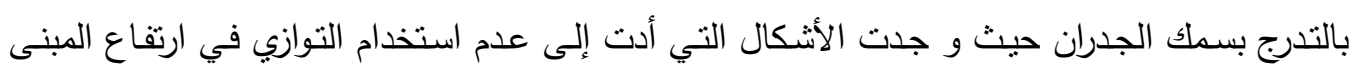
الأمر الذي أدى إلى زيادة حجم القاعدة و قلته كلما ارتقعنا إلى أعلى البيت، وقد وجدت هذه الصفة أيضـاً في البيوت القديمة للمدن الأثريـة القديمة مثل

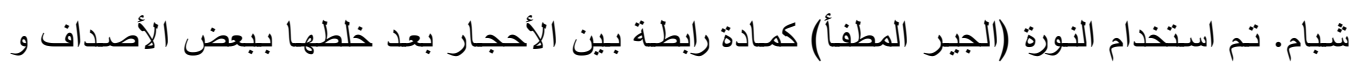

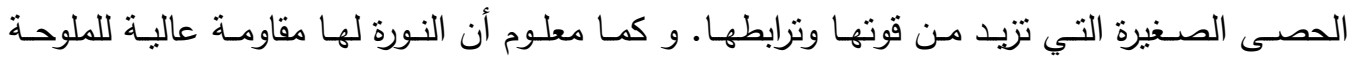

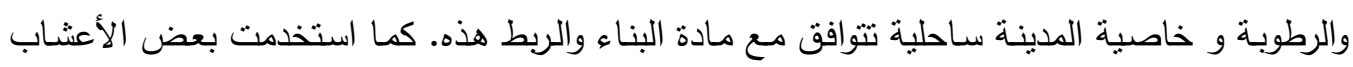
الصغيرة ( القش ) وهو ما يسمى( التبل). 


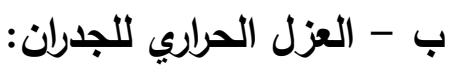

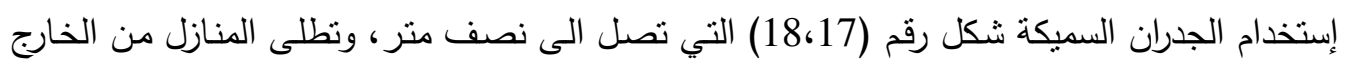

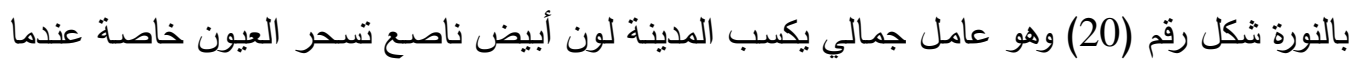

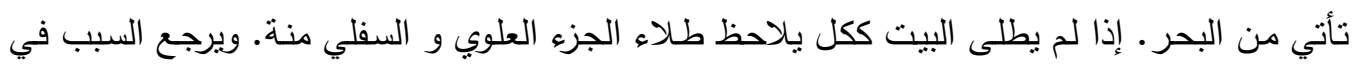

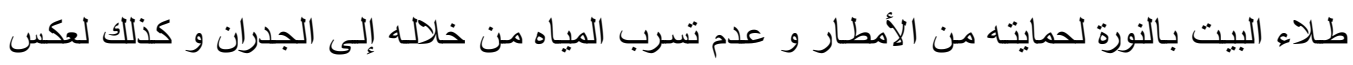

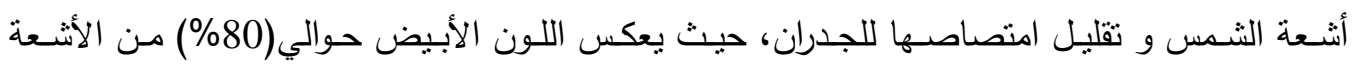
الثمسية الساقطة على المبنى. 4-3-3 نمط البناء المتلاصق وتعدد الطوابق وتوجية المباني:

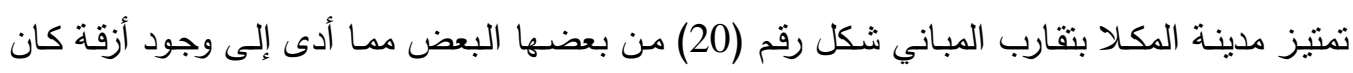

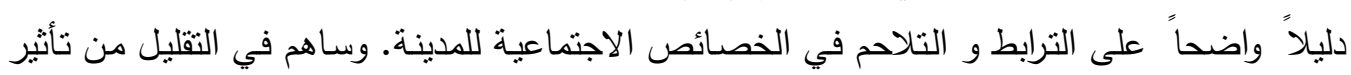

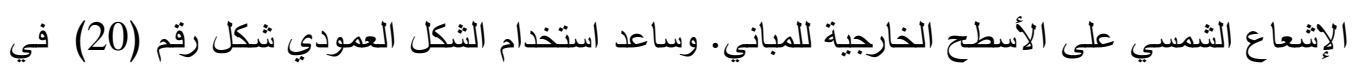

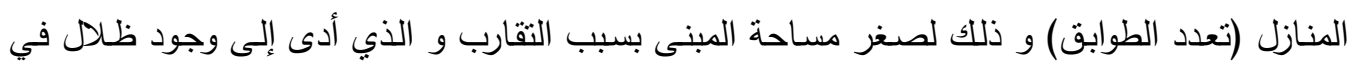

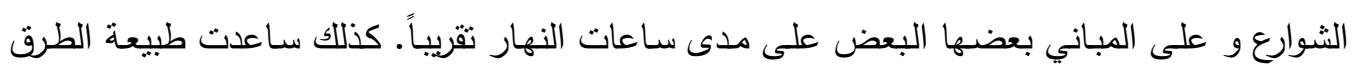

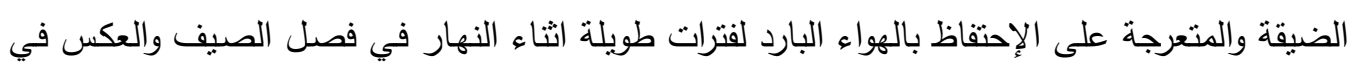

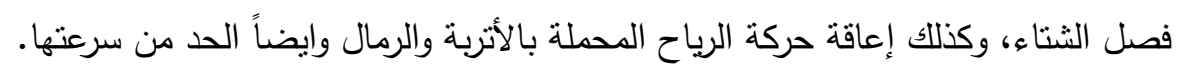

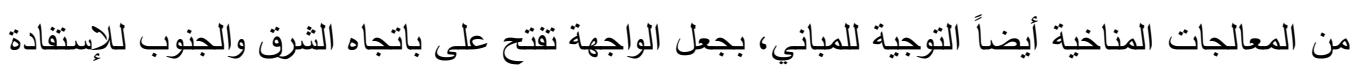

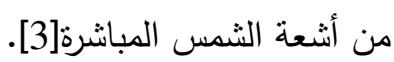

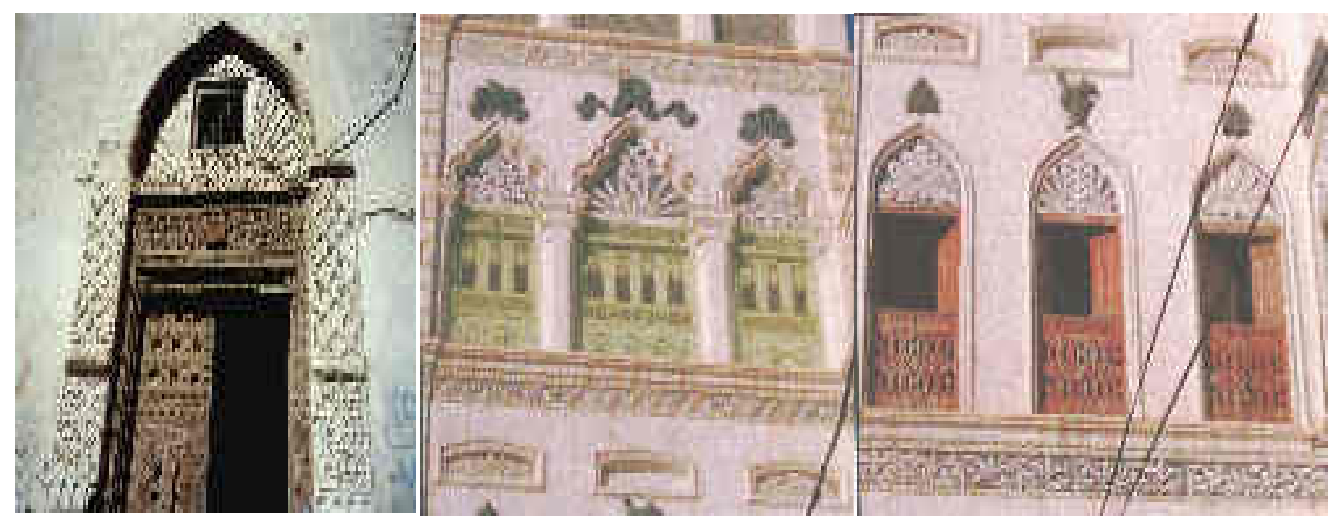

شكل رقم (19) يوضح نماذج من الفتحات والثبابيك

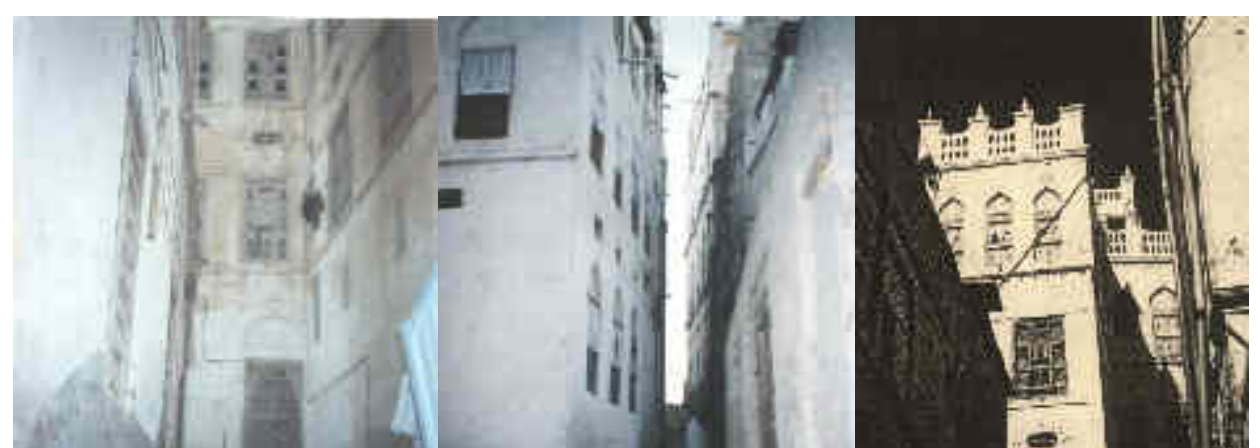


شكل رقم(20) يوضح طلاء واجهات المباني بالنورة ونمط البناء المتلاصق وتعدد الطوابق

\section{خامساً: الحماية والاستفادة من الطاقة الثمسية :}

تعتبر المناطق الحارة وخصوصا بمنطقة اليمن تتعرض للإشعاع الثمسي المباشر وذلك لصفاء الجو معظم شهور السنة وخصوصا في فصل الصيف مما يعرض المباني للحرارة الثديدة . 5-1-1 مدى الحماية من الطاقة الثمسية : عملية حماية المباني من أثنعة وحرارة الثمس هو الهدف الأساسي في المناطق الحارة عامة واليمن ومدينة المكلا خاصة وقد تم عرض أساليب الحماية من أشعة الثمس في المباني في البند السابق وأورده كما يلي :

استخدام الأفنية الداخلية ( التوجيه للاخل ): والذي يحقق عزل أنشعة الثمس عن معظم عناصر

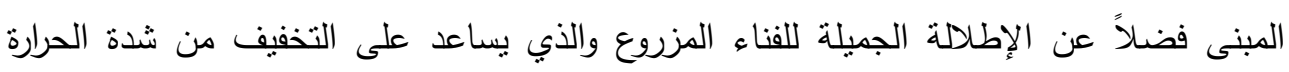

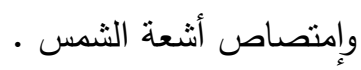
استخدام البروزات بالأدوار المتكررة : وهو ما يحقق نظليل نسبة كبيرة من الحوائط الخارجية للمبنى ويحقق التخفيف من حرارة الثمس .

استخدام المشربيات : كإسلوب عربي إسلامي لعزل أشعة الثمس والحماية منها من جهة وتحقيق

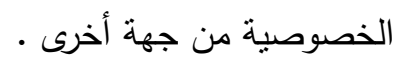
استخدام القمرية : والتي تستخدم كطابع معماري للمباني في العمارة اليمنية بصفة عامة وقي مدينة

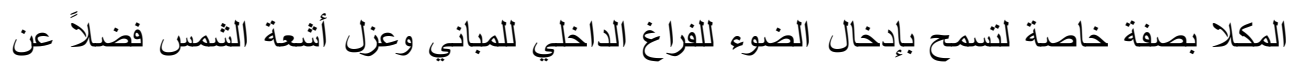

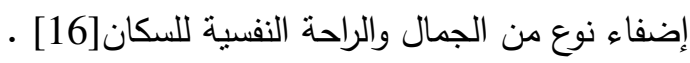
استخدام فتحات متتوعة وصغيرة لتحقيق التهوية : مثل الثواقيص ولحجب أنثعة الثمس مثل الكنة

استخدام الحوائط السميكة : والتي تحجب أثنعة الثمس المباشرة وتؤخر زمن وصول الحرارة الكامنة بها إلى الفراغ الداخلي ( وبمعنى آخر عزل الحرارة الخارجية ) مدينة شبام كمثال . 
صغر مساحة النوافذ بالمباني : والتي نساعد على التقليل من أنثعة الثمس النافذة إلى داخل

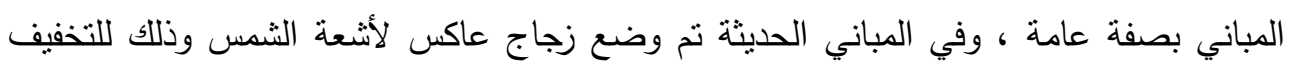

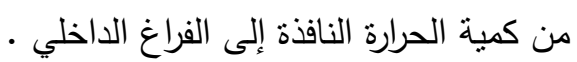
تحقيق الإظلال للمباني على بعضها البعض بنظام النسيج المتضام : وهو نظام تقسيم الأراضي

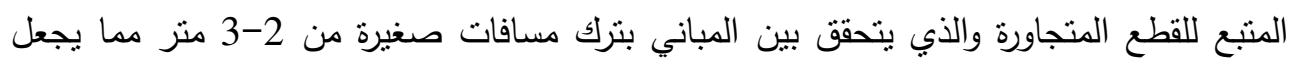
الإظلال واردا على واجهات المباني فترات أطول مع حركة الثمس نهاراً شكل (21) ـ
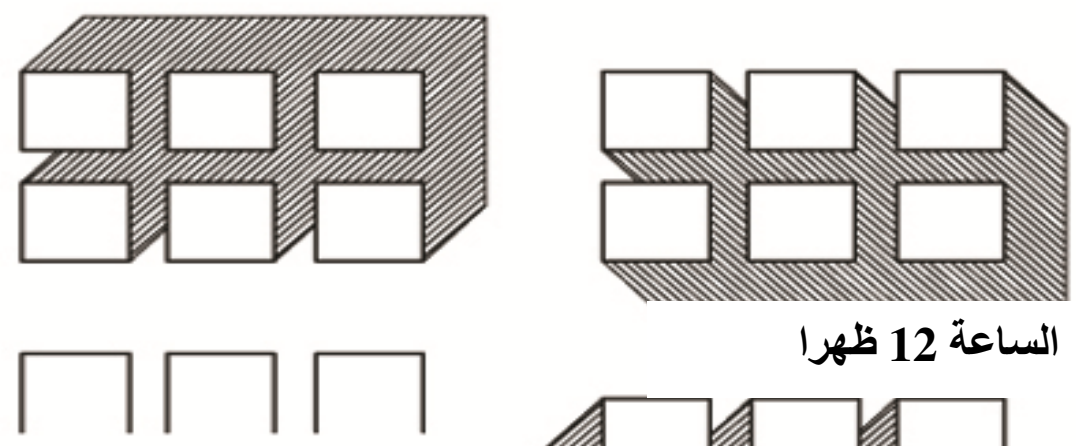

الساعة 12 ظهرا

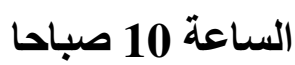

شارع

الساعة 4 عصرا

شكل رقم(21) يوضح نظام تقسيم الاراضي والبناء المنفصل بالمدينة (المكلا ) كمثال للمدينة اليمنية

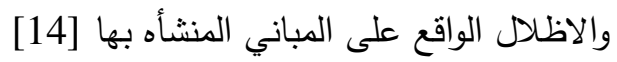

نظام التهوية الطبيعية باستخدام فكرة الفتحات المتقابلة للنوافذ بالمباني : وهي التي تحقق تحريك التي

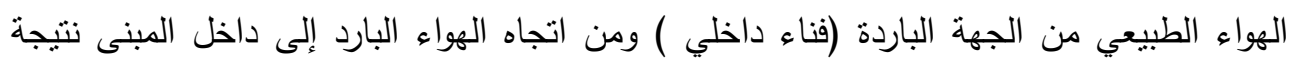
لخروج الهواء الساخن من الجهة الأخرى وهذه الفكرة نستخدم في المباني الحديثة والتي تعددت التياه طوابقها حتى بلغت عشرة طوابق بمدينة المكلا والمدن اليمنية .

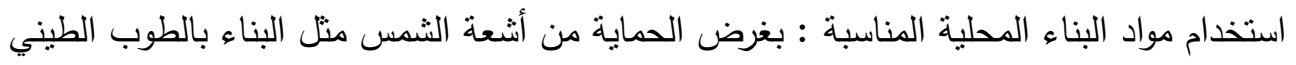
(مدن وادي حضرموت ومدينة شبام بصفة خاصة ) وكذلك إستخدام الحجر الطبيعي الجيري واللذان

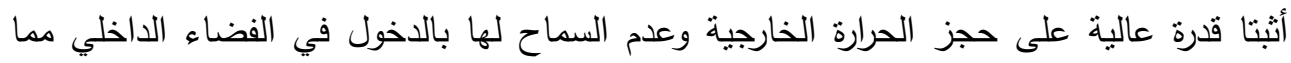

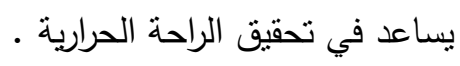
استخدام كاسرت الثمس : في المباني الحديثة بالمدينة نم إستخدام مواد أخرى من الخرسانة المسلحة والطوب الإسمنتي والمفرغ ولكن بإستخدام مواد عازلة للحرارة وإستخدام طرق العزل الحديثة 
لأشعة الثمس (كاسرات الثمس ) والتي تطبق في المنشآت الجديدة بأساليب مختلفة رأسية وأفقية ومركبة .

ملاقف الهواء : وهو أسلوب قديم لتهوية المباني للبلاد العربية ولكن بستخدم في بعض المباني

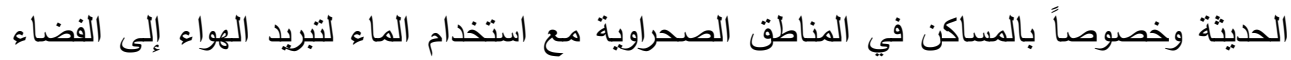
- الداخلي

\section{5-2-5 مدى الاستفادة من الطاقة الشمسية في المناطق الحارة:}

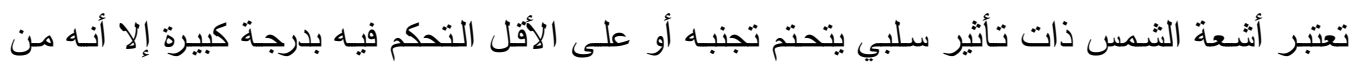

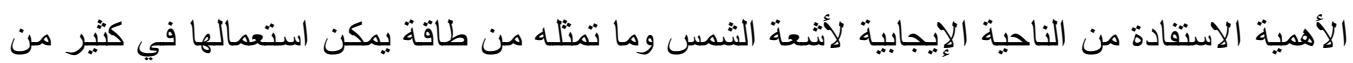

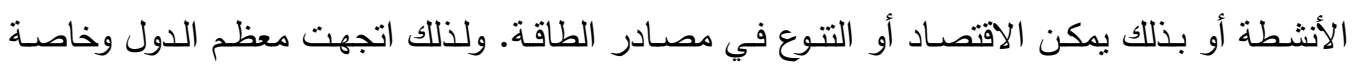

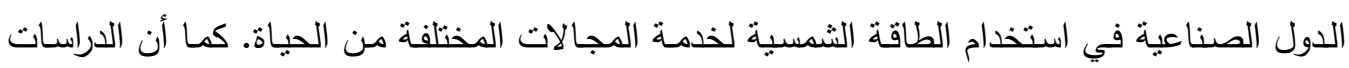

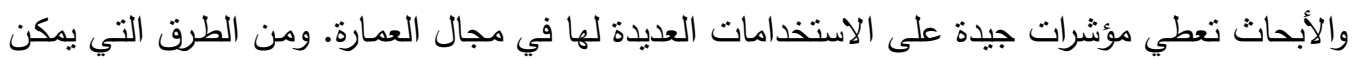
استخدامها للاستفادة من الطاقة الثمسية في المناطق الحارة (اليمن، المكلا) تدفئة ونبريد المباني(طريقة

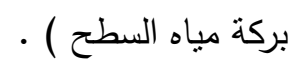

\section{5-2-5 تفئة وتبريد المباني(طريقة بركة مياه السطح):}

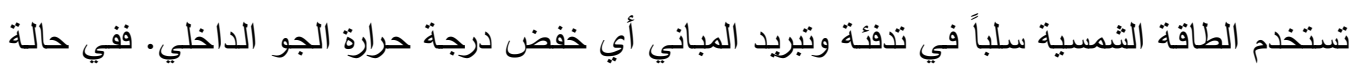
التذفئة يتم تجميع الطاقة الثمسية وتخزينها ثم إعادة توزيعها بواسطة الوسائل الثنلاث الأساسية للانتقال

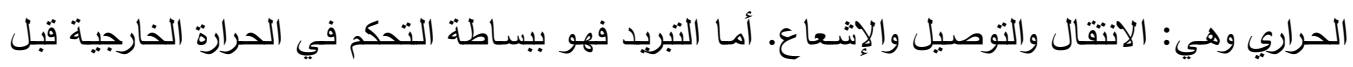
اختراقها بغلاف المبنى يكون ذللك في مصلحة التصميم. وفي هذه الطريقة يوضع الماء المختزن للحرارة على سطح المبنى (واحد) أو في أثناء تدفئة المبنى شتاء تتعرض كتلة الماء على السطح لأشعة الثمس مباشرة أثناء النهار لامتصاص الطناء الطاقة الحرارية واختزانها

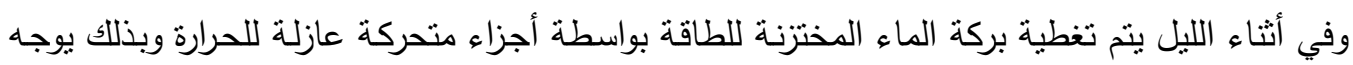

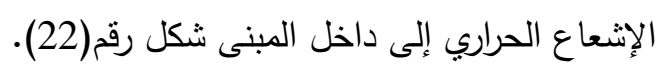

وفي الصيف تعكس هذه العملية حيث تمتص الحرارة الداخلية نهاراً بواسطة الماء الذي تتم تغطيته من

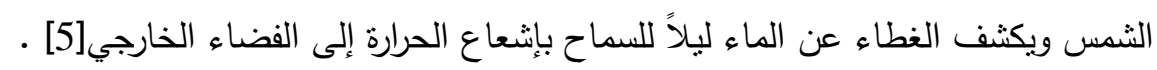
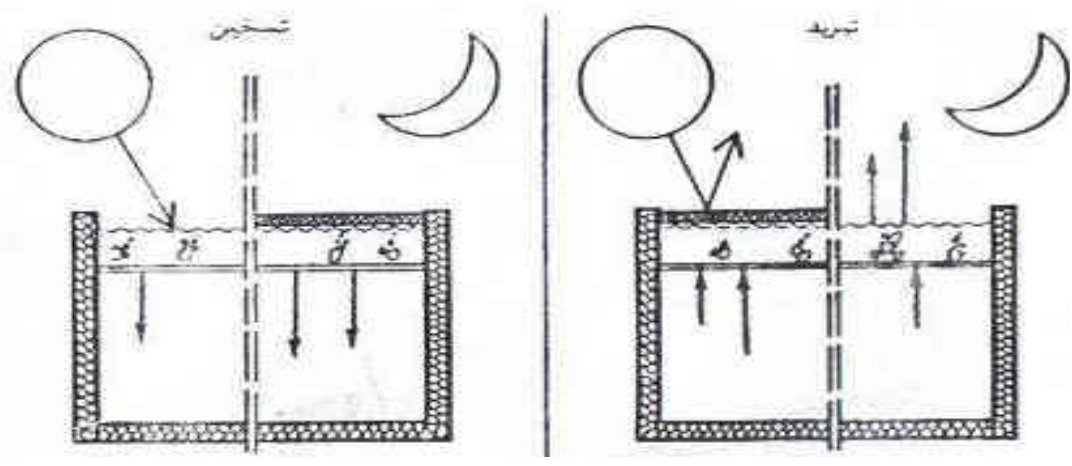
شكل رقم(22) يوضح فكرة طريقة بركة مياه السطح

2-2-5 2 استخدام المجمعات الشمسية :

أ - في تسخين المياة : ويتم ذلك باستخدام الطاقة الحراربة ، تلك الطاقة التي يتم الحصول عليها من

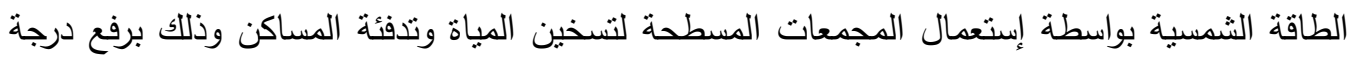
حرارة المياة إلى قرابة 60 درجة مئوية تستعمل المجمعات الثمسية المسطحة ذات النكات الثلفة الإقتصادية

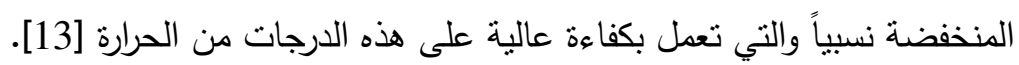

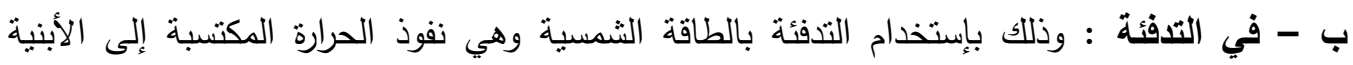
السكنية وغير السكنية ويتم ذلك عن طريق اللواقط ( المجمعات ) اللواقط السلبية لالتقاط الطاقة الثمسية

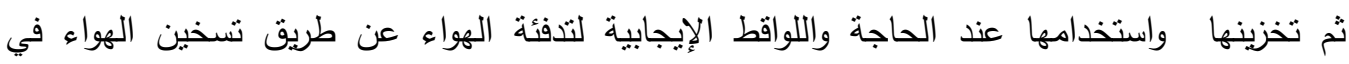

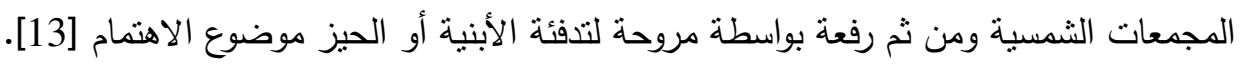

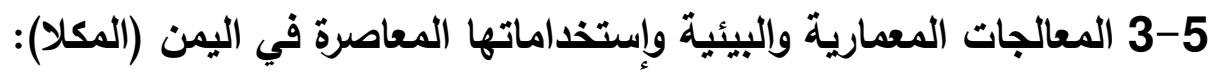
من خلال العرض السابق يمكن القول بان هناك نمط تخطيطي واضح وعديد من المفردات المبات المعمارية

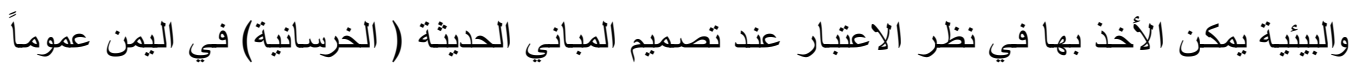

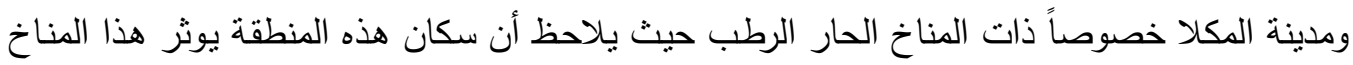

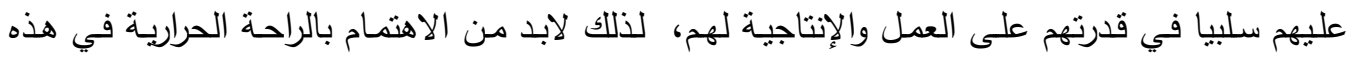

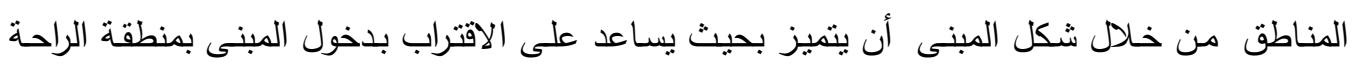

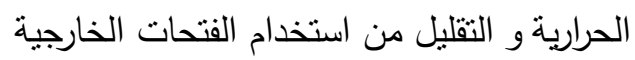
اللمبنى واستخدام الفنحات الضيقة بحيث تعمل على تقليل الحرارة المكتسبة من المناخ الخارجي ولابد من

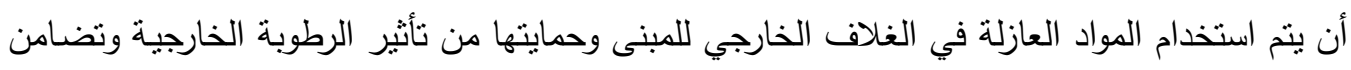

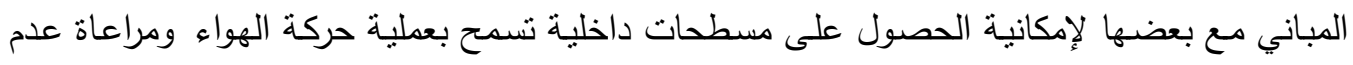
استخدام الهياكل الخرسانية النقبلة الني يكون لها توصيلية حرارية كيبرة و استخدام وحدات التكييف بحيث تساعد على الدخول إلى الراحة الحرارية للمبنى.

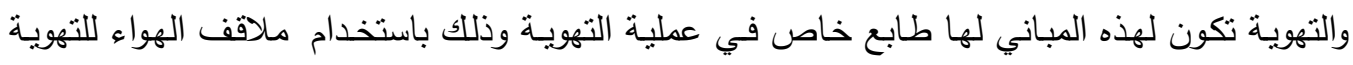

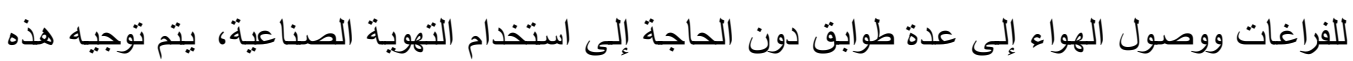
الملاقف ناحية الهواء السائد بالمنطقة للحصول على أقصى تهوية للفراغات الفات الداخلية. واستخدام الأفنبة

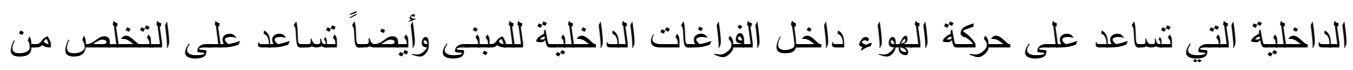




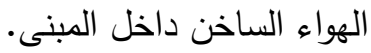

واستخدام العناصر المعمارية وتراثها الذي كان احد الحلول لهذه المناطق وذللك باستخدام المشربيات التي

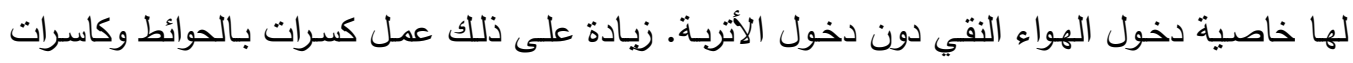

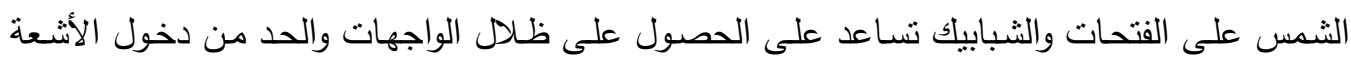

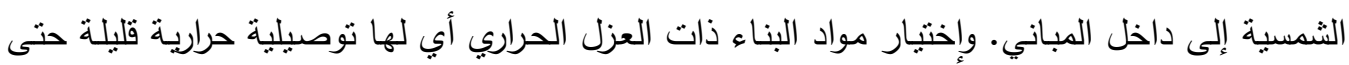

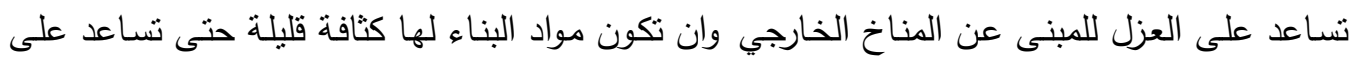
تقليل التوصيلية الحرارية لمواد البناء وتأثيرها على فراغات المبنى الداخلية[3].

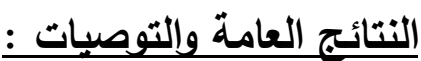

\section{أولاًا : أهم النتائج المستخلصة : المهابه}

إن عمارة المناطق الحارة عمارة ذات طابع مميز نستخدم فيه الأفنية الداخلية كعنصر أساسي لعلاج حالة المناخ وتهيئة البيئة الداخلية للمسكن بصفة خاصة والمباني العامة والخدمية والإدارية بصفة الدانة عامة وكمثال نم عرض من المغرب في مدينة أغادير مثلما يوجد بمدينة المكلا.

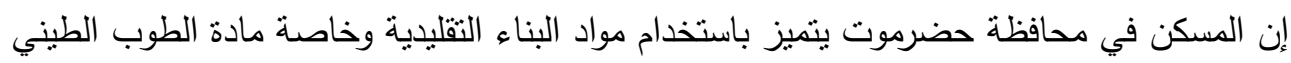

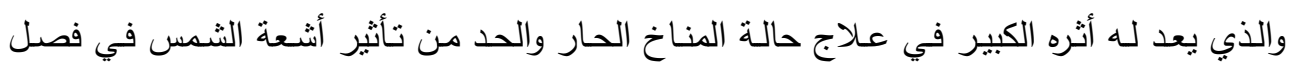
الصيف.

إنه يوجد علاج لحالة المناخ الحار في البلاد التي تقع في المنطقة الحارة والقريبة من خط الإستواء

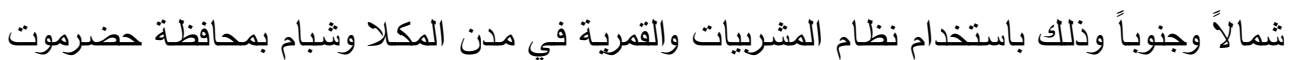
وفي مصر والمملكة العربية السعودية وغيرها... كنلك تم إستخدام معالجات بالواجهات منها بروزات الطوابق للخارج بالطوابق العليا لتحقيق الإظلال على الواجهات وكذلك الثخشيخة العلوية للتهوية وملاقف الهواء وإستخدام كاسرات الثنمس الرأسية والأفقية في المباني الحكومية والعامة وكذلك السكنية في مصر والمملكة العربية السعودية.

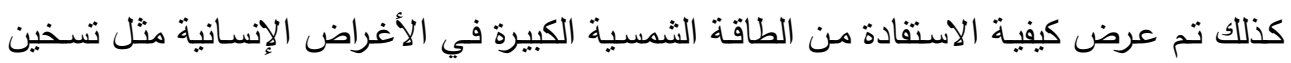

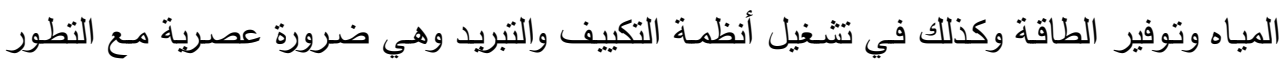
التكنولوجي الحادث في العالم وخصوصاً عند البناء بمواد البناء الحديثة.

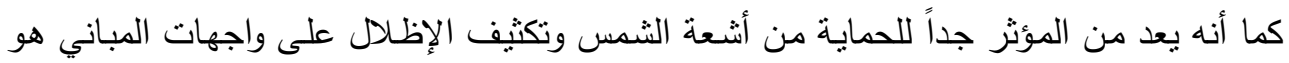

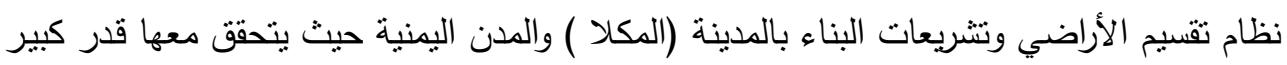
من الإظلال يحقق الحماية من أثنعة الثمس والطاقة الحرارية الصادرة منها على المباني السكنية .

\section{ثانياً : أهم التوصبيات :}

أن يراعى المعماريون والمختصون في المجالس المحلية تطبيق أسس تصميم المباني وعلاج حالة 
البيئة الحارة في وضـع العناصر المعماريـة المناسبة سواء باستخدام الفناء الداخلي أو في عـلاج

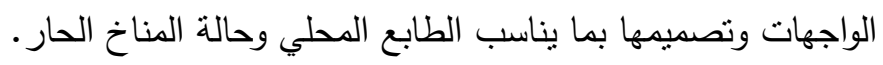

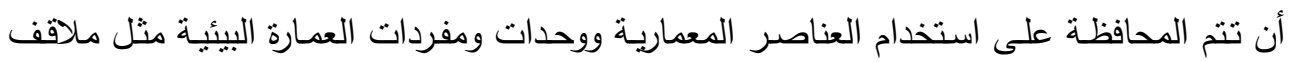
الهواء، الثخشيخة والقمرية باعتبارها طابعا محليا يحقق التتمية المستدامة بالمباني الحديثة في مدينة

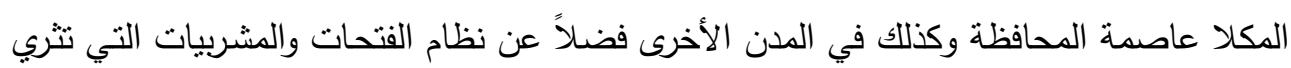
البناء المعماري المتميز للعمارة اليمنية.

أن يتم إنشاء جهاز متخصص في مراقبة الإنشاءات الحديثة وإعطاء التراخيص مع الالتزام بتحقيق

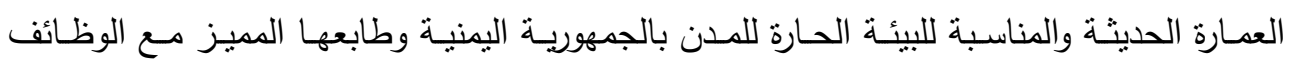
الجديدة الناشئة عن الخدمات وتتوعها في العصر الحديث.

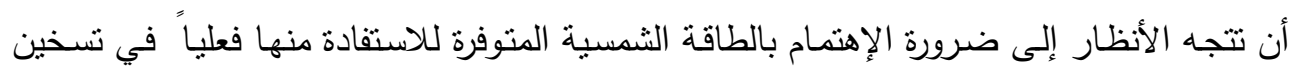
المياة وكذلك في التدفئة في المواقع الباردة شتاءً والعمل على الاستفادة منها في تدفئة وتبريد المباني العامة والخدمات بطاقة شمسية اقتصادية ومتاحة .

\section{قائمة المراجع العلمية:}

1. الجوهي، محمد سالم، أثشهر الراحة ومتطلبات الوصول إلى الراحة وعلاقتها بالعمران - ورقة

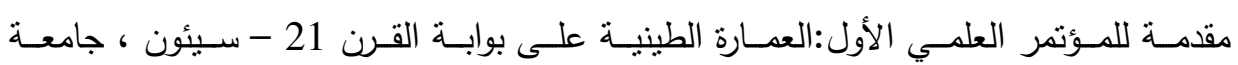

$$
\text { حضرموت،2000م، ص ص 99 9 - } 104 .
$$

2. السقاف، أحمد محمد، باوزير، نادر عبد الرحيم، المشكلات البيئية في مدينة المكلا ورقة علمية

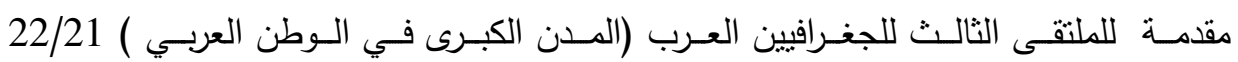

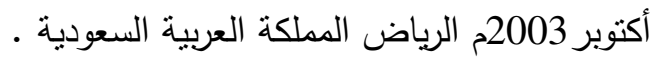

3. السقاف، محمد عبداله، وآخرون، قسم الهندسـة المعماريـة والتخطيط البيئي - كليـة الهندسـة 3. 2008 4. إسماعيل، عبد القادر عسـاج محمد، مناخ اليمن، مركز عبادي للاراسـات والنشر ، صنعاء، اليمن،1999م، أبماعي،

5. الوكيل، شفق العوضي، وسراج، محمد عبد الله، المناخ وعمارة المناطق الحارة، الطبعة الثالثة،

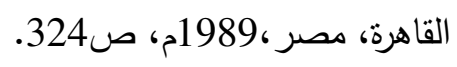

6. بن عوف، سعيد عبد الرحيم سعيد، العناصر المناخية والتصميم المعماري، جامعة الملك سعود،

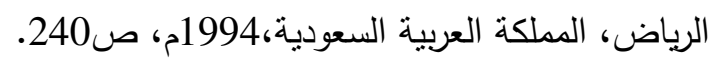

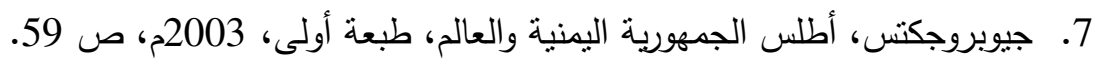


8. عبد المنطلب ، محمد علي ،العـارة التلقائيـة بجنوب الوادي بين النظريـة والنطبيق لعمارة

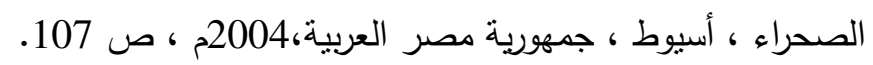

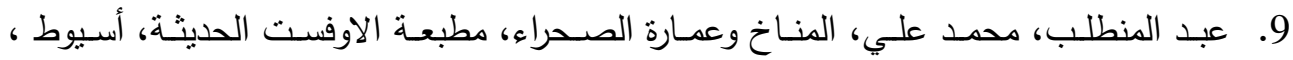

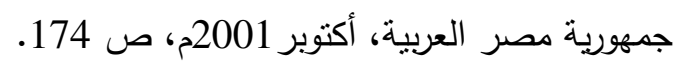

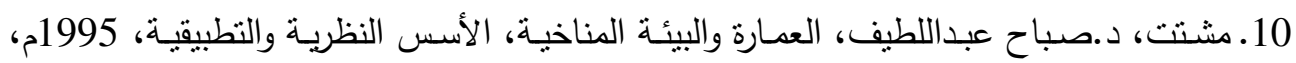

$$
\text { ص ص212. }
$$

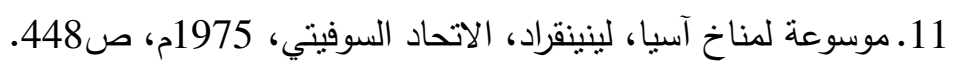

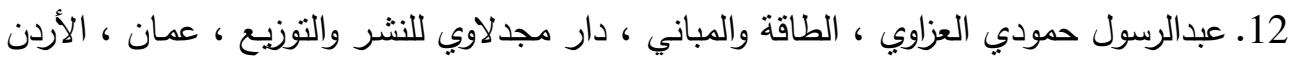

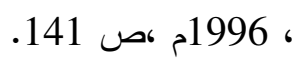

13.زهير جبور ، حسـام بركـات ، علوم البيئة ، كليـة الهندسـة ،جامعـة البعتث ، مديريـة الكتب

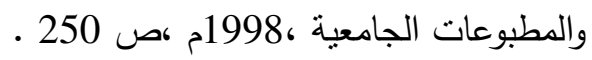

14. Shading Analyser Computer programs, Copyringht, (C) MBS, Lab, School of Architecture USC, Version 1.0.0, 1999.

15. Michele Melaragno:" Wind In Architectural And Environmental Design", New York, Van Nostrand Reinhold Company, 1982. 